\title{
Dizin travmatik çıkıkları
}

\section{Traumatic dislocations of the knee}

\author{
M. Uğur Mermerkaya, Metin Polat, Altuğ Tanrı̈ver, Reha Tandoğan, Asım Kayaalp \\ Çankaya Ortopedi, Kavaklıdere, Ankara
}

Travmatik diz çıkıkları değişken prognozlu sık görülmeyen ciddi ortopedik yaralanmalardır; bu yaralanmaların teşhis ve tedavi yöntemleri tartışmalı idi. Erken dönemde yapılan uygun tedavinin uzun dönem fonksiyonel sonuçlar üzerinde önemli etkisi olduğu gösterilmiştir. Burada, bizim halihazırdaki yaklaşımımızın yanı sıra, güncel literatüre ilişkin kapsamlı bir gözden geçirme de sunulmuştur. Travmatik diz çıkığı; diz yaralanmalarında gözden kaçabilen, yüksek oranda klinik şüphe ile tanı konulan bir durumdur. Travmatik diz dislokasyonlarında son dönemde yapılan araştırmalar sonucu; cerrahi gerekliliğine ve cerrahi tekniklere, vasküler tetkiklere ve rehabilitasyon protokollerine duyulan ihtiyaç ve zamanlama konusunda günümüzde bir derece konsensüs sağlanmış bulunmaktadır. Nörovasküler komplikasyonlar için dikkatli monitorizasyon, uygun araştırmalar ve diz bağ yaralanmalarında uzman bir cerrahi ekibin erken müdahalesi bu zor yaralanmaların başarılı yönetiminde anahtardır.

Anahtar sözcülkler: diz çıkıkları; diz bağ yaralanmaları; çoklu bağ yaralanmaları

T ravmatik diz, çıkığı tüm ortopedik yaralanmaların \%0,2'sinden daha az prevalans ile, oldukça nadir görülen bir yaralanmadır. Ancak, \%50'si şiddetli ligamentöz yaralanma nedeniyle spontan redükte olduğu için, gerçek prevalansı belli değildir. ${ }^{[1]}$ Diz çıkıkları izole yaralanmalar olarak görüldüğünde tanı konması nispeten kolayken; multi-travmalı, şuuru kapalı hastada özellikle spontan redüksiyon gerçekleşmişse; tanı konulması gecikebilir. Bu da eşlik eden popliteal arter yaralanmasının fark edilememesine ve hatta ekstremitenin kaybına bile neden olabilir. Bütün multi-travmalı hastalarda diz stabilitesi kontrol edilmeli, instabilite varsa vasküler muayene yapılmalı ve normal olsa bile yakından takip edilmelidir. Diz çıkıklarında artroskopinin farklı rolü vardır. Bunlardan ilki, tanıdaki önemli rolüdür. Diz çıkığı sonrası meydana gelen bağ yaralanmalarından sonra yaralanan yapıları tanımlama
Traumatic knee dislocations are uncommon yet serious injuries that historically have had variable prognosis. The evaluation and management of traumatic knee dislocations remains controversial. Appropriate early management has been shown to have a significant impact on long term functional outcome. A comprehensive review of the recent literature is presented alongside our current approach to management. The dislocated knee is an under diagnosed injury which relies on a high index of clinical suspicion on presentation of any knee injury. Due to the results of recent studies on traumatic knee dislocations, there is now a degree of consensus regarding the need for and the timing of surgery, vascular investigations, surgical techniques and rehabilitation protocols. Vigilant monitoring for neurovascular complications, appropriate investigations and early involvement of surgeons experienced on knee ligament surgeries is the key to successful management of these difficult injuries.

Key words: knee dislocation; knee ligament injury; multiple ligament injury

ve tedavi planı oluşturmada direkt grafiler ve manyetik rezonans (MR) görüntüleme çok değerli bilgiler vermesine rağmen, eklem içi yaralanmanın tanısında artroskopi altın standarttır. Artroskopinin diğer rolü, çapraz bağlara yönelik onarım ve rekonstrüksiyonların artroskopik olarak gerçekleştirilmesidir. Yaralanmayı takip eden 2-3 haftada sinoviyal sızdırmazlık sağlandıktan sonra, çapraz bağ rekonstrüksiyonları güvenli bir şekilde artroskopik olarak yapılabilir. Yine aynı cerrahi sırasında, eşlik eden menisküs ve kıkırdak lezyonlarının tedavisi de artroskopik olarak yapılabilir. İşlemlerin bu yöntemle yapılması, zaten travmatize olmuş bir dizde açık cerrahinin yaratacağı ilave morbidite ve cilt nekrozu riskini de azaltmış olur. Son olarak; cerrahi tedavi sonrasında gelişebilecek enfeksiyon veya artrofibrozis gibi komplikasyonların tedavisinde de artroskopinin önemli bir işlevi vardır.

- İletişim adresi: Dr. M. Uğur Mermerkaya, Bülten sokak No:44, 06700, Çankaya, Ankara

Tel: 0532 - 3346696 e-posta: drugurmermerkaya@gmail.com

- Geliș tarihi: 9 Kasım 2018 Kabul tarihi: 9 Kasım 2018 


\section{TANIM}

Diz çıkığı tanım olarak tibio-femoral eklem bütünlüğünün bozulmasıdır. Eklem bütünlüğünde meydana gelen bu bozulma, iki veya daha fazla diz bağının yaralandığı çoklu bağ yaralanması olarak kabul edilir: ön çapraz bağ (ÖÇB), arka çapraz bağ (AÇB), postero-lateral köşe (PLK), (lateral kollateral, popliteus ve popliteofibular bağ), iç yan bağ (IYYB). Bunlar içinde en sık görülen ÖÇB ve İY yaralanmasının ayrı bir yeri vardır. IYYB'nin yüksek iyileşme yeteneği nedeniyle daha iyi prognoza sahip olan bu yaralanma dışındaki tüm durumlar diz çıkığı olarak kabul edilmeli ve tedavi edilmelidir. ${ }^{[2]}$ Yaralanmanın şiddeti, yönü ve süresine bağıı olarak diz çevresindeki neredeyse her yapının yaralanması söz konusu olabilir. Bu kadar geniş bir yelpazedeki yaralanmaları sınıflamak çok kolay değildir. ilk olarak Kennedy tarafından 1963 yılında, tibianın femura göreceli yönelimine dayanılarak yapılan anatomik sınıflandırma geliştirildi (anterior, posterior, lateral, mediyal, rotatuvar / antero-mediyal, postero-mediyal, antero-lateral, postero-lateral). ${ }^{3]}$ Bu sınıflama basit olmasına karşın prognoz ve tedavi planı açısından yeterli olmamıştır. Bugün en yaygın kabul gören sınıflama Schenck tarafından yapılmıştır (Tablo 1 ). ${ }^{[4]}$

\section{EPIDEMIYOLOJiK ÖZELLIKLER}

Diz çıkığı oldukça nadir görülen yaralanmalardandır. Tüm ortopedik yaralanmaların \%0,02-0,2'sini oluşturur. Genç erkeklerde kadın hastalara oranla dört kat fazla görülmektedir. Bu yaralanmaların \%75'ine yüksek enerjili trafik kazaları neden olmaktadır. Geriye kalan \%25'lik kısmını ise düşük enerjili spor yaralanmaları ve düşme meydana getirmektedir. Bilateral diz çıkığı tüm diz çıkıklarının yaklaşık olarak \%5'ini oluşturur. ${ }^{[1,2]}$ Diz çıkıklarının hepsine çoklu bağ yaralanmaları eşlik eder. Arom ve ark., 11 milyon hasta içeren bir veri tabanında, 100 hasta yılı için 0,072

Tablo 1. Schenck sınıflaması

\begin{tabular}{ll}
\hline KD I & Bir çapraz bağ sağlam diz çıkı̆̆ı \\
KD II & İki çapraz bağ yırtık, yan bağlar intakt \\
KD III & Iki çapraz bir yan bağ yaralanması \\
KD III M & Mediyal \\
KD III L & Lateral \\
KD IV & Tüm bağlar yırtık \\
KD V & Kırıklı çıkık \\
Alt grup & $C$ (damar) N (sinir) yaralanması
\end{tabular}

gibi bir oran saptamışlardır; bunların \%17'si açık yaralanmalardır. ${ }^{[5]}$ Düşük ya da yüksek enerjili yaralanmalar sonucu ortaya çıkabilir. Düşük enerjili yaralanmalar, genellikle bir sportif aktivite sırasında ortaya çıkan doğrudan ve dolaylı yüklerin sonucudur. Düşük enerjili yükler ile oluşan çoklu bağ yaralanmaları sırasında damar yaralanması riski oldukça düşüktür. Buna karşın trafik kazası, göçük altında kalma, endüstriyel kazalar gibi yüksek enerjili yaralanmalarda damar hasarı riski \%65'lere kadar çıkabilir. ${ }^{6]}$

Obez hastalarda görülen ve basit travmalar sonrası oluşan çoklu bağ yaralanmalarını ayrı olarak değerlendirmek gerekir. Werner ve ark., "ultra low velocity" diz çıkığı olarak tanımladıkları ve sıklıkla kadın olan bu hasta grubunda, nörovasküler yaralanma riskinin ve cerrahi sonrası komplikasyon oranının daha yüksek olduğunu bulmuşlardır. ${ }^{[7]}$ Georgiadis ve ark.'nın 53 olguluk serilerinde, morbid obez hastalarda sinir hasarı ve damar onarımı gerektiren yaralanmaların daha yüksek oranda olduğu saptanmıştır. ${ }^{[8]}$ Benzer şekilde Ridley ve ark., 126 hastalık çoklu bağ yaralanması serilerinde, vücut kitle indeksindeki her bir birim artış için komplikasyon riskinin \%9,2 oranında arttığını bildirmişlerdir. ${ }^{[9]}$

\section{ILK DEĞERLENDIRME VE EŞLIK EDEN YARALANMALAR}

Diz çıkığı yaralanması geçiren bir hastanın tedavisi, mümkünse yaralanmanın olduğu anda ve yerde başlamalıdır. ilk olarak ileri travma yaşam destek (ATLS) protokolleri uygulanmalı ve hastanın genel durumu değerlendirilmelidir. Önce hastanın yaşamsal bulguları stabilize edilmeli, iç organ ve kafa travmasına yönelik incelemesi acilen gerçekleştirilmelidir. Ekstremitenin dolaşımı ikinci önceliğe sahiptir. Becker ve ark., 106 olguda diz çıkığı sonrası gelişen çoklu bağ yaralanmasına eşlik eden yaralanmaları incelemişlerdir. ${ }^{[10]}$ Olguların \%25'inde aynı taraf tibia plato kırığı, \%19'unda femur kırığı, \%13'ünde intraabdominal yaralanma, \%10'unda şiddetli kafa travması, ve \%10'unda semptomatik pulmoner emboli bulmuşlardır. ${ }^{[10]}$ Diz çıkıklarının yarısı kendiliğinden redükte olur bu nedenle acilde bu yaralanmalar atlanabilir. Yaralanma sahasında ilk değerlendirmede çıkık fark edildiyse nazik bir manevra ile redükte edilmelidir. Redükte edilebildiyse hafif fleksiyonda atele alınmalı ve süratle en yakın acil servise nakledilmelidir. Redüksiyon öncesi ve sonrası nörovasküler durumun belgelenmesi gerekir. Redükte edilemeyen çıkıklar veya redüksiyon sonrası gelişen kompartman sendromu, damar yaralanması gibi durumlar acil olarak tedavi edilmesi gerekmektedir. Açık çıkıkların acil debridmanı ve gerekirse eksternal fiksatör ile 
tespiti şarttır. Kendiliğinden redükte olmayan çıkıkların kapalı redüksiyonu her zaman mümkün olmayabilir. Femur mediyal kondilinin mediyal kapsülü düğme deliği gibi delip çıktığı ve mediyal kondilin distalinde ciltte girinti ile tespit edilen gamze belirtisi (dimple sign) varlığı, redükte edilemeyen çıkıklar için patogonomik bir bulgudur. Cilt nekrozunu önlemek amacıyla bu durumda acil açık cerrahi gerekir. ${ }^{[11]}$

\section{Damar Yaralanmasının Değerlendirilmesi}

Popliteal arter, anatomik yerleşimi nedeniyle diz çıkığı yaralanmaları sırasında belirgin yaralanma riski altındadır. Popliteal arter yaralanmaları, basit intimal hasardan tam kopmaya kadar geniş bir aralıkta olabilir. Çoklu diz bağ yaralanmalarında popliteal arter yaralanması insidansı \%4-64 arasında rapor edilmiştir. ${ }^{[12]}$ Özellikle PLK yaralanmalarında dolaşım sorunu açısından dikkatli olunmalıdır. Kapiller dolum varlığı yeterli değildir ve nabızların (dorsalis pedis ve tibialis posterior arterleri) palpe edilmesi şarttır. Siyanoz, solukluk ve kapiller dolumda bozulma gecikme var ise majör damar yaralanması düşünülmelidir. ${ }^{[13]}$ Basit bir tanı yöntemi, ayak bileği/brakiyal kan basıncı indeksi$\operatorname{dir}(\mathrm{ABI})$. Bu oranın 0,90'ın altında olmasının damar yaralanması tanısında yüksek duyarlılığa sahip olduğu gösterilmiştir. ${ }^{[14]} \mathrm{ABI} 0,90$ 'ın altında ise veya damar yaralanması konusunda bir şüphe varsa acil anjiyogram yapılması yararlıdır. Ancak, tanı konusunda bir şüphe yoksa veya redüksiyon sonrası nabızlar alınamıyorsa anjiyografi ile vakit kaybedilmemelidir, zira ilk sekiz saatte dolaşım sağlanamaz ise ampütasyon oranı $\% 80$ 'lere kadar çıkar. Yaralanmanın yeri popliteal bölgededir ve postero-mediyal kesi ve karşı dizden alınan ven grefti ile damar onarımı en uygun seçenektir. [15]

Diz çıkıkları sonrası damar yaralanması değerlendirilmesinde altın standart yöntem anjiyografidir. Anjiyografi nispeten pahalı bir tetkiktir ve trombüs oluşumu, kanama, arterio-venöz fistül oluşumu, psödoanevrizma, kontrast maddeye reaksiyon ve böbrek yetmezliği gibi komplikasyonları vardır. Bu komplikasyonların genel görülme olasılığı \%1,7 civarındadı[ ${ }^{[15]}$ ve $\% 2,4-7$ oranında yalancı pozitiflik riski vardır. ${ }^{[16-18]}$ Alternatif olarak, kasık yerine kübital fossadan bilgisayarlı tomografi (BT) anjiyografi yapılabilir ve çeşitli çalışmalarda \%100 duyarlı ve özgül olduğu bulunmuştur. ${ }^{[19-21]}$ Arteriyel Doppler ultrasonografi daha ucuz maliyetlidir ve anjiyografiye alternatif olarak kullanılabilir; ancak acil durumlarda uygulanması zor olduğu gibi, yapan kişinin deneyimi ile orantılı doğru sonuç verecektir. ${ }^{[19,22]}$

Nabızların alınıyor olması arteriyel yaralanma olmadığını göstermez, kollateral dolaşım tam bir popliteal arter tıkanmasını maskelenmesine neden olabilir.
Tekrarlayan muayeneler ve ABI ölçümleri ile olası bir damar yaralanması takip edilmelidir. Bu hastalarda, intimal hasara bağlı geç trombüs oluşumu ve kompartman sendromu açısından uyanık olunmalıdır. Damar onarımı yapılan hastalarda genellikle reperfüzyon hasarını önlemek için fasyatomi gereksinimi olur. Fasyatomi sonrasında, yumuşak doku örtüsünün devamlılığı sağlanana kadar bağ cerrahisi yapılması doğru değildir. Damar onarımı sırasında birkaç basit kapsüler dikiş ile dizin stabilitesi arttırılabilir, ancak rekonstrüksiyon tekniklerinden kaçınılmalıdır. Damar onarımı sonrası eklem dizlik içinde stabil ise bu şekilde takip edilebilir. Dizlik içinde redükte olmayan dizler, damar onarımını korumak ve yumuşak doku iyileşmesine katkıda bulunmak açısından dizi kateden geçici anterior eksternal fiksatörler ile izlenmelidir (Şekil 1). Bağ cerrahisi, yumuşak doku iyileşmesi sağlandıktan sonra ileri dönemde yapılmalıdır.

\section{Cilt ve Yumuşak Dokuların Değerlendirilmesi}

Cilt ve yumuşak doku örtüsü dikkatlice değerlendirilmelidir. Basit ekimoz ve sıyrıklar çok önemli değildir; mümkünse cerrahi kesileri buradan uzakta yapıp, allogreft kullanarak kesi sayısı ve uzunluğu azaltılmalıdır. Doku kaybı varsa önce seri debridmanlar sonrasında greft-flep uygulaması ve en sonunda kronik dönemde bağ cerrahisi uygun olacaktır.

\section{Sinir Yaralanmalarının Değerlendirilmesi}

Diz çıkığına bağı yaralanmalarda, aynı popliteal arter gibi, peroneal sinir de anatomik olarak yaralanmaya çok elverişlidir. Siyatik sinirin dalı olan ortak peroneal sinir, PLK'ye girer ve biseps tendon arkasından dönerek fibula boynunun etrafinda periost üzerinde $6 \mathrm{~cm}$ boyunca ilerler. Tibial sinir yaralanmaları da görülebilirse de peroneal sinir kadar sık değildir. Çoklu bağ yaralanmalarında peroneal sinir hasarı insidansı \%16-50 oranında bildirilmiştir. ${ }^{[23]} \mathrm{Bu}$ yaralanmalar, basit paresteziden komplet motor ve duyu kaybına kadar geniş bir yelpazede görülebilir.

Diz çıkı̆̆ı olan hastalarda tam bir nörolojik muayene yapılmalıdır. Tam motor peroneal felç durumunda hasta, ayak bileği dorsifleksiyonu, ayak eversiyonu ve başparmak eversiyonunu yapamayacaktır. Ayak dorsalinde de duyu kaybı oluşacaktır. Nadiren sinir kılıfında oluşan hematom da sinir fonksiyon bozukluklarına yol açabilir. Bu nadir durumun da göz ardı edilmemesi ve tespiti halinde, sinirin dekomprese edilmesi gerekir. Cerrahi dekompresyon ile hemen olumlu sonuç beklenmemelidir. Erken yaşlarda olan hasarın geri dönme olasılığı daha fazladır. Peskun ve ark.'na göre, erkek cinsiyet, vücut kitle indeksinin fazla olması ve fibula kırığı varlığında peroneal sinir lezyonu daha sıktır. ${ }^{[24]}$ Genel 


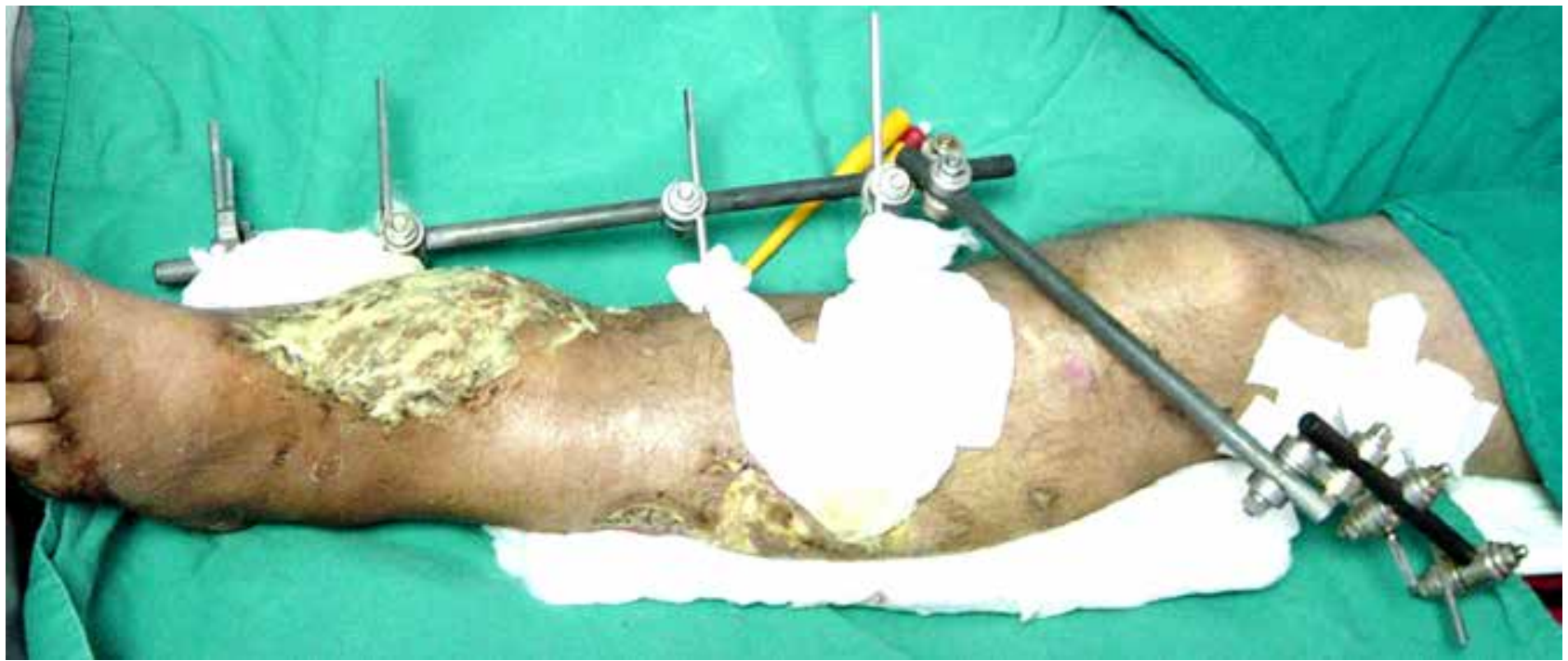

Şekil 1. Yumuşak doku yaralanması olan ve damar tamiri yapılmış bir diz çıkığında dizi kateden eksternal fiksatör uygulaması.

olarak sinir lezyonlarının fonksiyonel olarak geri dönme olasılığı \%20-40 civarındadır. ${ }^{[25,26]}$ Cerrahi sırasında sinir devamlılı̆ı saptansa bile geri dönüş her zaman tam değildir. Elli beş olguluk bir çoklu bağ yaralanması serisinde 14 (\%25) peroneal sinir lezyonu saptanmış, 6-18 ay arası bir sürede $\% 21$ olguda tam düzelme, \%29 olguda kısmi düzelme saptanırken, olguların yarısında hiç düzelme olmamıştır. ${ }^{[27]}$ Sinir hasarı saptandığında, ayağı nötral dorsifleksiyonda tutacak bir ortez kullanılmalı, kalan kas gruplarının kuwvetlendirilmesi, posterior kapsülün gerdirilmesi ve esnetilmesi egzersizleri ile kontraktürlerin önüne geçilmeye çalışılmalıdır. ${ }^{[26]}$ Segmenter sinir kayıplarında sinir greftlemesinin sonuçları başarılı değildir. ${ }^{[23]}$ Bir yılın sonunda hiç motor dönüş olmaz ise ayak bileği dorsifleksiyonunu sağlamak için tibialis posterior transferi yapılabilir. ${ }^{[26]}$

\section{Eşlik Eden Kırıkların Değerlendirilmesi}

Diz çıkı̆̆ına bağlı gelişen çoklu bağ yaralanmalarına diz çevresinde çeşitli kırıklar eşlik edebilir. Bunlardan bir kısmı bağlar veya kapsülün yapışma yerinden olan avulsiyon kırıklarıdır ve çoklu bağ yaralanmalarının dolaylı göstergelerindendir. ${ }^{[28]}$ Twaddle, çoklu diz bağ yaralanmalarında tamir edilebilir avulsiyon kırıklarını ÖÇB için \%19, AÇB için \%51, iYB için \%64 ve dış yan bağ (DYB) için \%84 olarak rapor etmiştir. ${ }^{[29]}$ Bazı yüksek enerjili yaralanmalarda tibial kenar çökme kırıkları oluşabilir. Özellikle PLK yaralanmalarında mediyal tibial plato kenar kırıkları görülebilir. ${ }^{[30]}$ Dizin stabilitesinin sağlanması için bu kırıkların tespiti şarttır. Başka bir bakış açısıyla değerlendirildiğinde, tibia plato kırıklarına da değişen oranlarda bağ yaralanmaları eşlik eder. Stannard, Schatzker kırık tipine göre değişmekle beraber, tibia plato kırıklarına eşlik eden bağ yaralanmalarını \%45-85 arasında görülebildiğini ve yüksek enerjili Tip IV, V ve VI kırıklarda bağ lezyonu oranının daha yüksek olduğunu belirtmiştir. ${ }^{[31]}$

\section{Diğer Yaralanmalar}

Çoklu bağ yaralanmalarında dizde kıkırdak ve menisküs yaralanmaları çok sık görülür. Krych ve ark.'nın 122 hastalık çoklu bağ yaralanması serisinde, olguların \%55'inde menisküs, \%48'inde kıkırdak hasarı olduğu, \%76'sında ise ya menisküs ya da kıkırdak hasarı görüldügü rapor edilmiştir. ${ }^{[32]}$ Yaralanmadan cerrahiye kadar geçen süre uzadıkça, çoklu kompartmanlarda kıkırdak hasarı ortaya çıkma riski artar. Patellar tendon yırtıkları, patella çıkığı, osteokondral kırıklar, menisko-kapsüler ayrılmalar da çoklu bağ yaralanmalarına eşlik edebilir.

\section{BAĞ YARALANMALARINDA FiZiK INCELEME}

Diz çıkığına bağı gelişen çoklu bağ yaralanmalarında ilk değerlendirmede bağların ön değerlendirilmesinin yapılması önemlidir. Muayene mutlaka sağlam diz ile karşılaştırılmalı yapılmalıdır. Erken dönemde dizdeki ağrı ve ödemden dolayı muayeneyi yapmak zor olabilir. Unutulmamalıdır ki tekrarlayan muayeneler de damar sinir yaralanmasına neden olabilir veya bu yaralanmaları arttırabilir. Zaman içinde bazı dokularda iyileşmeler olabileceğinden, esas muayene genel anestezi altında ameliyat masasında yapılacak olandır. Bu sırada ÖÇB, AÇB, IYB, DYB ve PLK ayrıntılı olarak değerlendirilmelidir. 


\section{Ön Çapraz Bağ (ÖÇB)}

ÖÇB, tibianın femur altında öne translasyonunda esas engelleyicidir ve yırtıklarının tanısını koymada Lachman testi en duyarlı ve özgün testtir. ${ }^{[33,34]}$ Bu test, supin pozisyonda diz 20-30 ${ }^{\circ}$ fleksiyondayken yapılır. Uyluk kaslarını gevşetmek için kalça hafif fleksiyona ve dış rotasyona getirilir. Femur lateral taraftan sabit pozisyonda tespit edilirken, tibia mediyalden diğer el yardımı ile öne çekilmeye çalışılır. Muayeneye tibianın redükte pozisyonundan başlanmalıdır. AÇB'nin kopuk olması tibiada arkaya düşmeye neden olabilir ve yalancı pozitiflik verdirebilir. Femura göre tibianın öne deplasmanı şu şekilde sınıflandırılır: Evre 1, 0-5 mm; Evre 2, 6-10 mm; Evre 3, 11-15 mm. Muayene sırasında tibiayı öne çekerken sert bir sonlanma olması, bağın sağlam olduğuna bir işarettir. Ön çekmece ve pivot shift testleri de kullanılabilir, ancak unutulmamalıdır ki özellikle pivot shift testi çoklu bağ yaralanmasında değişen diz biyomekaniği nedeniyle güvenilir olmayabilir. ${ }^{[19,33]}$

\section{Arka Çapraz Bağ (AÇB)}

AÇB yaralanması arka çekmece testi, arkaya çökme (posterior sag) bulgusu, kuadriseps aktif testi ve PLK yaralanması ile kombine olarak dial testi ile değerlendirilir. AÇB yaralanmasının tespiti için en doğru test arka çekmece testidir. Diz 70-90 fleksiyonda, hasta supin pozisyonda iken yapılır. ${ }^{[34]}$ Anterior tibial plato teste başlarken femur kondillerinin $1 \mathrm{~cm}$ önündeki normal pozisyonunda olmalıdır, değerlendirmenin evrelemesi tibianın posterior translasyonuna göre yapılır. Diğer yumuşak dokuların durumu aynı ÖÇB yaralanmasında olduğu gibi sonucu etkileyebilir. Yaralanmanın derecelendirilmesi aşağıdaki şekildedir: Evre I, translasyon <5 $\mathrm{mm}$; Evre II, 5-10 mm (femur ve tibia ayn hizaya gelir); Evre III, translasyon $>10 \mathrm{~mm}$. Evre III aynı zamanda ek bağ yaralanmalarının olduğunun göstergesidir. ${ }^{[19,35-37]}$ Pozitif posterior çökme, diz $90^{\circ}$ 'de iken ek bir güç uygulanmadan tibianın femur ön yüz çizgisinden geriye doğru düşmesidir. Bu pozisyonda muayene eden kişi ayağı sabitler ve hastaya kuadrisepsini kasmasını isterse, tibia öne doğru gelerek redükte olur; buna da pozitif kuadriseps aktif testi denir.

\section{Postero-lateral Köşe (PLK)}

PLK dizin her fleksiyon açısında, dizin ana eksternal tibial rotasyon stabilizatörüdür. PLK genellikle $A C ̧ B$ ve DYB ile birlikte Dial testi ile değerlendirilir. Bunun dışında eksternal rotasyon rekurvatum testi ve postero-lateral çekmece testi, ters pivot shift testi de kullanılabilir. PLK'nin yaralanmaları gözden kaçırılırsa diğer yapılan bağ rekonstrüksiyonları da başarısız olacaktır. ${ }^{[38]}$ PLK yaralanmaları sıklıkla AÇB yaralanmaları ile birlikte olduğundan muayene eden kişinin yaralanma mekanizmasını ve belirtileri çok iyi irdelemesi ve PLK yaralanmasından şüphelenmesi gerekir.

Varus zorlama testi, $0^{\circ}$ ve $30^{\circ}$ fleksiyonda yapılmalıdır ${ }^{[39]} ; 0^{\circ}$ de pozitif olan varus açılması, sıklıkla DYB hasarına eşlik eden bir PLK ve ÖÇB yaralanmasının göstergesidir. İzole PLK yaralanmaları $30^{\circ}$ fleksiyonda maksimum varus açılmasına neden olur.

Dış rotasyon, en sık Dial testi (postero-lateral rotasyon testi) ile değerlendirilir. Bu test ile AÇB ve PLK değerlendirilir. Supin veya pron pozisyonda yapılabilir. Diz $30^{\circ}$ ve $90^{\circ}$ fleksiyondayken hastanın ayağı dış rotasyona getirilir. Diz $30^{\circ}$ 'de fleksiyondayken, karşı dize göre $10^{\circ}$ 'den fazla dış rotasyon varlığı PLK yaralanmasının göstergesidir. Aynı muayene $90^{\circ}$ 'de tekrarlandığında dış rotasyonda artma varsa bu kombine PLK/ AÇB yaralanmasını işaret eder. ${ }^{[40]}$

Eksternal rotasyon rekurvatum testinde, muayeneyi yapan kişi yaralı bacağı hastanın başparmağından tutup muayene masasından kaldırır. Bu sırada tibianın femura göre eksternal rotasyona gelip rekurvatuma gitmesi PLK yaralanmasını gösterir (Şekil 2).

Postero-lateral çekmece testinde, diz $80^{\circ}$ fleksiyondayken tibia platosuna posterior ve dış rotasyon yönünde kuvvet uygulanır. Lateral tibial platonun mediyal platoya göre dış rotasyona ve posteriora yer değiştirmesi pozitif sonuç olarak yorumlanır ve AÇB/PLK yaralanmasını gösterir. Ters pivot shift testinde ise diz $90^{\circ}$ fleksiyondan ekstansiyona getirilirken valgusa zorlanır ve aynı anda ayağa eksternal rotasyon uygulanır. iliotibial bandın fleksörden ekstansöre dönüşmesi ile $20-30^{\circ}$ 'de posteriora sublukse lateral tibial plato ani olarak redükte olur. ${ }^{[41]}$

\section{Yan Bağlar}

İzole IYB ve DYB yaralanmalarının muayenesinde sırasıyla valgus ve varus zorlama testleri uygulanır. Bu testler $0^{\circ}$ ve $30^{\circ}$ fleksiyonda tekrarlanır. Eğer $30^{\circ}$ fleksiyonda pozitif olan test tam ekstansiyonda kayboluyorsa, izole yan bağ yaralanmasını işaret eder. Tam ekstansiyonda da pozitif olan test, $30^{\circ}$ 'de artıyorsa yan bağ yaralanmasına çapraz bağ ve posterior kapsüler yapıların da hasarı eklenmiş demektir. Evre I yaralanmalarda 0-5 $\mathrm{mm}$, Evre II yaralanmalarda $5-10 \mathrm{~mm}$ ve Evre III yaralanmalarda 10 mm'den fazla laksite gözlenir.

\section{GÖRÜNTÜLEME YÖNTEMLERi}

Diz çıkıklarının radyografik değerlendirilmesine ön arka ve yan grafiler ile başlanmalıdır. Kronik olgularda uzun bacak aks grafisi ile varus valgus dizilim bozuklukları değerlendirilebilir. Çoklu bağ yaralanmalarında, 

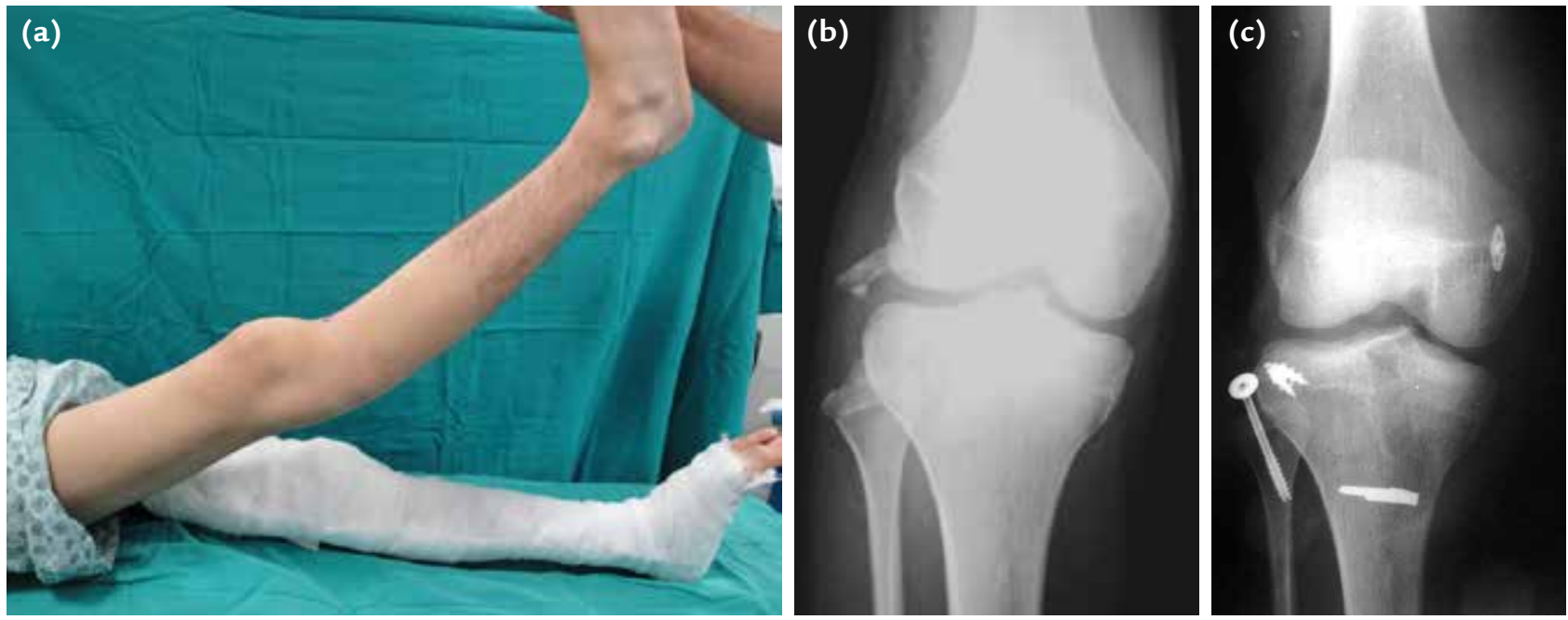

Şekil 2. a-c. AÇB ve PLK yaralanması olan bir hastada eksternal rotasyon rekurvatum testi. Ayak parmaklarından tutulup bacak kaldırıldığında, tibianın postero-laterale sublukse olduğu görülmekte (a). Aynı hastanın direkt grafısinde fibula başından avulsiyon kırı̆̆ (b). AÇB rekonstrüksiyonu ve fibula başı avulsiyonunun tespiti sonrası grafi (c).

dizin disloke/sublukse olarak kalmış olması nadir de olsa görülebilir (Şekil 3). Buna karşın diz çevresinde küçük avulsiyon kırıklarının varlı̆̆ı, çoklu bağ yaralanmaları için tipiktir. Kapsül veya bağların kemiğe yapışma yerinden olan bu kırıklar dizdeki ciddi bağ hasarının göstergesidir. ${ }^{[19,28,42,43]}$ Segond kırığı, ÖÇB yırtığı ile birlikte olan lateral kapsüler bağın (antero-lateral bağ) lateral tibial plato yapışma yerinden kopma kırığıdır. Ters Segond kırığı ise AÇB ve menisküs yaralanmaları ile ilişkilidir ve mediyal tibial platodaki derin mediyal kollateral bağ (MKL) liflerinin avulsiyon kırığıdır. ${ }^{[28]}$ DYB/PLK yaralanmalarında fibula başından kopma kırıkları görülebilir (Şekil 2). Grafilerde, AÇB'nin tibial yapışma yerinden olan kopma kırıkları ve daha nadir olarak ÖÇB'nin tibial eminensiyadan kopma kırıkları da saptanabilir. Bazen çok ince bir kemik parçası ile ortaya çıkan bu kırıklar, grafi kalitesi yetersiz ise gözden kaçabilir. Direkt grafilerde ayrıca tibia plato kırıkları veya distal femoral osteokondral kırıkları tespit edilebilir.

Direkt grafilerin bir başka kullanım alanı zorlamalı grafilerdir. Zorlamalı grafilerin akut dönemde yapılması doğru değildir, yaralanmayı arttırma riski vardır. Zorlamalı grafilerin asıl kullanım alanı kronik yaralanmaların tanısının konulması ve laksite miktarının objektif olarak ölçülmesidir (Şekil 4). Özellikle tedavi öncesi ve sonrası zorlamalı grafilerdeki laksite mikta$\mathrm{r}$, cerrahi sonucunun değerlendirilmesinde en doğru ve tekrarlanabilir sonucu verecektir. ÖÇB için radyolojik olmayan artrometrik ölçümler kullanılabilir. Ancak, $A C ̧ B, P L K$ ve yan bağların değerlendirilmesi için zorlamalı grafiler çekilebilir. AÇB yırtıkları için tarif edilmiş çeşitli zorlamalı grafi teknikleri mevcuttur. ${ }^{[44-46]}$ Bunlar dışında, erken takiplerde açı ayarlı dizlik içinde çekilmiş ortoröntgenogramlarda dizin hafif sublukse olması, eksternal tespit için endikasyon olabilir. ${ }^{[19,47]}$

BT, eklemi ilgilendiren kırıkların varlığında tedavi planlaması için gereklidir. Sadece bağ yaralanması olan olgularda BT'nin yeri yoktur. MR görüntüleme, çoklu bağ yaralanmalarının değerlendirilmesinde vazgeçilmezdir, ancak acil şartlarda genellikle gerekli değildir. MR ile menisküs lezyonları, eklem kıkırdağı, popliteus tendonu, patellar tendon yaralanmaları ayrıntılı olarak incelenebilir. $\mathrm{Bu}$, hem kesilerin planlanması hem de gerekli greft materyallerinin hazırlanması açısından önem taşır. MR ayrıca patella çıkıklarını ve peroneal siniri değerlendirmede de yardımcıdır. Eksternal fiksatör uygulama planı varsa MR uyumlu olmasına dikkat edilmelidir.

\section{ACIL TEDAVi}

Acil tedavi yaklaşımında önce hastanın yaşamını etkileyebilecek kafa içi, toraks ve batın yaralanmaları değerlendirilip müdahale edilmelidir. Ekstremitenin dolaşımı ortopedik tedavinin ilk sırasında yer alır. Kapalı redükte edilemeyen çıkıklar, arteriyel yaralanma veya kompartman sendromu, 'gamze belirtisi' olması durumunda acil cerrahi endikasyon vardır. Hastanın dizi çıkık olarak acil servise geldiyse sedasyon altında acil şartlarda kapalı redüksiyon denenmeli sonrasında $A B I$ ve nabızlar tekrar değerlendirilmelidir. Eğer halen çıkık devam ediyorsa kapalı veya açık redüksiyon için 

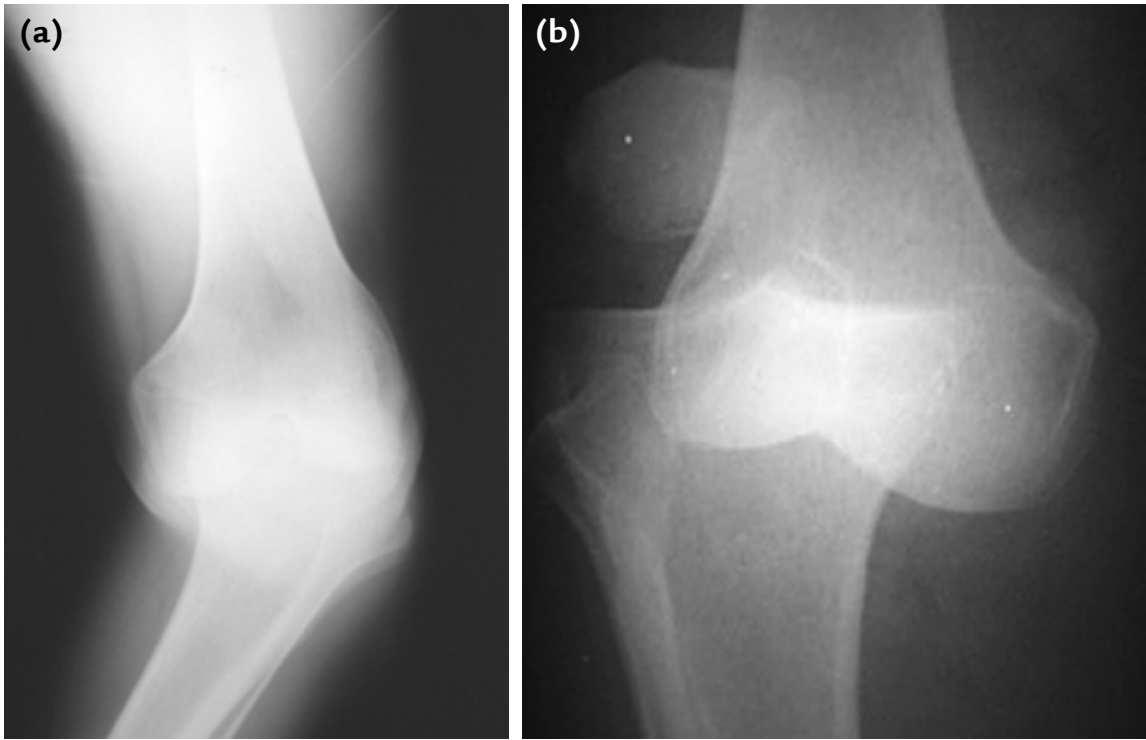

Şekil 3. a, b. Direkt grafilerde diz çıkığı örnekleri.

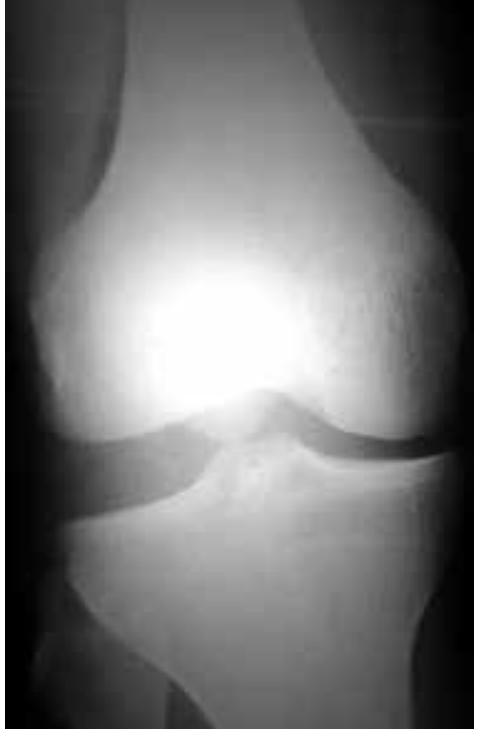

Şekil 4. Kronik PLK yaralanması olan bir olguda varus zorlama grafisi ile lateral kompartmandaki anormal açılma gözlenmekte. ameliyathaneye alınmalıdır. Redüksiyon ve nörovasküler durumun değerlendirilmesi sonrası, ağrı kontrolü, stabilite ve yumuşak dokulardaki ödemin geçmesi için immobilizasyon gerekir. Bu işlem için sıklıkla "immobilizer" tipi dizlik yeterli olur. Dizlik içinde diz redükte tutulamıyorsa veya damar yaralanması için cerrahi gerekiyorsa immobilizasyon için eksternal fiksatör kullanılmalıdır. Damar onarımı sonrasında re-perfüzyon hasarına bağlı gelişebilecek kompartman sendromunu önlemek için profilaktik fasyatomilerin uygulanması gerekir. Damar cerrahisi sırasında bağ rekonstrüksiyonu yapmak cerrahi süreyi uzatabilir ve genellikle uygun değildir. Ancak, kapsüler dokular ve bağlara birkaç basit dikiş ile onarım yapılması dizin stabilitesine katkıda bulunacaktır ve süreyi uzatmayacak şekilde yapılabilir. Bu tamir sonrasında diz hâlâ instabil ise eksternal fiksatör uygulanmalıdır. Acil revaskülarizasyon için popliteal arterden by-pass greftleme veya ters çevrilmiş bir safen grefti kullanılabilir. Damar onarımı yapılan hastalarda bağ rekonstrüksiyonu, fasyatomiler kapatılıp yumuşak doku örtüsü bütünlüğü sağlandıktan ve damar tamiri olgunlaştıktan sonra yapılmalıdır; bu süre altı aydan kısa değildir. Hastada damar yaralanması bulguları ilk muayenede tespit edilmediyse bile ilk 48 saat nabızların yakın takip edilmesi intimal hasara bağIı geç tromboz açısından dikkatli olunmalıdır. Dikkatli klinik takip ve gerekirse anjiyogram yapılması yeterlidir, her olguya rutin arteriyografi şart değildir. ${ }^{[16,48]}$

Eksternal fiksatör uygulaması, açık diz çıkığı, dizlik veya atelde redüksiyonun sağlanamaması ve damar onarımı sonrasında endikedir. Kullanılan eksternal fiksatör MR uyumlu olmalıdır ve çivi giriş yerlerinin tünel yerleşim yerlerinden en az $10 \mathrm{~cm}$ uzakta olması önerilir. ${ }^{[49]}$ Eğer dizlik veya atel ile stabilizasyon sağlanabiliyorsa, tibianın arkaya yer değiştirmesini önlemek için $20^{\circ}$ fleksiyonda uygulanması gerekir.[50] İmmobilizasyon sonrası redüksiyonun korunduğunu doğrulamak için radyolojik kontrol yapılmalıdır.

Sonraki aşamada hastaya MR görüntüleme yapılarak, yaralanan bağlar ve eşlik eden yaralanmalar değerlendirilerek ciddi bir planlama yapılmalıdır. Geçmiş yıllarda uygulanan konservatif tedavi ya kabul edilemez laksite ya da artrofibrozis ile sonuçlandığı için günümüzde kullanımı sınırlıdır. Ancak ileri yaşta ve cerrahi tedavinin komorbiditeler nedeniyle mümkün olmadığı olgularda konservatif yöntem uygulanabilir. Çoklu bağ yaralanmalarının güncel tedavisi cerrahi olarak bütün yaralanmış yapıların onarımı veya rekonstrüksiyonudur. Bu işlem tek sefer veya aşamalı cerrahiler ile yapılabilir. ${ }^{[51]}$ Literatürdeki bütün çalışmalarda cerrahi tedavinin sonuçları konservatif tedaviye üstün bulunmuştur. ${ }^{[47,51-56]}$

\section{AKUT ÇOKLU BAĞ YARALANMALARINDA ARTROSKOPI}

Diz çıkı̆̆ına bağlı akut çoklu bağ yaralanmalarının tanı ve tedavisinde artroskopinin önemli bir yeri vardır. Yaralanmadan iki hafta geçtikten ve sinoviyal sızdırmazlık sağlandıktan sonra güvenle artroskopi yapılabilir. Yine de sıvının eklem dışına kaçması konusunda dikkatli 
olunmalı ve pompa kullanımından kaçınılmalı, sık sık bacak kompartmanlarının gerginliği kontrol edilmelidir. Akut yaralanmalarda artroskopi tanı ve tedavi amaçı uygulanabilir. Bağ yaralanmalarına eşlik eden kıkırdak ve menisküs yaralanmalarının tanı ve tedavisi artroskopik olarak yapılabilir. Bağ yaralanmasının olduğu kompartmanın karşı tarafındaki yaralanmalar için artroskopi, ilave bir kesiye gerek kalmaksızın tanı ve tedavi imkânı sağlar. Zaten artrofibrozis riskinin yüksek olduğu bu yaralanmalarda ek bir artrotomiden kaçınılması önemli bir avantajdır. Artroskopik inceleme sırasında mediyal ve lateral eklem aralığının patolojik açılması değerlendirilerek yaralanmanın şiddeti hakkında bilgi sahibi olunur. Menisküsler tibiaya bağı ise menisko-tibial bağlar sağlamdır. Menisküsler sıklıkla olduğu gibi femura yakın ve tibiadan ayrıımışsa, menisko-tibial bağ yaralanması vardır ve onarılması gerekir. Sonuç olarak akut çoklu bağ yaralanmalarının cerrahi tedavisinde ilk basamak tanısal artroskopi olmalıdır. Sinoviyal sızdırmazlık sağlanmadan cerrahi yapılacaksa, kuru artroskopi veya kısa süreli bir tanısal artroskopi yapılabilir.

Akut çoklu bağ yaralanmalarında artroskopinin ikinci rolü, çapraz bağların onarımıdır. Bu onarım periostal soyulma (peel-off) yaralanmalarında primer tamir, avulsiyon kırıklarında internal tespit ve bağın gövdesinden olan yaralanmalarda bağın rekonstrüksiyonu şeklinde olabilir.

\section{Zamanlama}

Çoklu bağ yaralanmalarının cerrahi tedavisinde zamanlama konusunda çelişkili görüşler vardır. Yaralanmadan sonraki 3-4 haftada cerrahiyi savunan yazarların savı, bu süre geçtikten sonra oluşan fibrozis nedeniyle, yaralanmış yapıların tanımlanması ve anatomik onarımının zor olmasıdır. Erken cerrahi ile primer onarım imkânı varken, geç cerrahide onarımdan çok rekonstrüksiyon gündeme gelmektedir. Gecikmiş cerrahiyi savunan yazarlar ise bu hastalarda artrofibrozis ve diz hareket kısıtlıı̆̆ının daha az olduğunu savunurlar. Literatürde her iki görüşü savunan çalışmalara da rastlamak mümkündür. Levy ve ark., beş çalışmanın sistemik derlemesinde, erken cerrahi ile daha yüksek Lysholm skorları (82'ye karşılık 90), daha yüksek oranda IKDC (International Knee Documentation Committee) mükemmel/iyi sonuç (\%31'e karşılık \%47) ve daha yüksek sportif aktivite (Knee Outcome Survey Activities of Daily Living Scale -KOS-ADL) skorları (69'a karşılık 89) saptamışlardır. ${ }^{[4]}$ Yazarlar, erken cerrahiyi tavsiye ederken; her türlü cerrahi tedavinin konservatif tedaviden daha iyi olduğunu da eklemişlerdir. Buna karşın Mook ve ark., 24 geriye dönük çalışmanın sistematik derlemesinde, akut cerrahinin gecikmiş cerrahiye göre daha yüksek oranda hareket kısıtlılığı ile sonuçlandığını bulmuşlardır. ${ }^{[52]}$ Yazarlar, gecikmiş cerrahi ile de akut cerrahi kadar iyi stabilite elde edilebileceği ve instabil dizlerde cerrahi öncesi harekete başlamanın sonuçları olumsuz etkilemediği kanısına varmışlardır. Ancak ilginç olarak, kronik ve akut dönemde cerrahi yapılan olgularda anestezi altında manipülasyon ve artroliz oranları benzerdir. Yaralanmaların nadir görülmesi ve çok farklı yaralanma şekillerinin bir arada değerlendirilmeleri nedeniyle, çoklu bağ yaralanmalarında cerrahinin zamanlaması konusunda kanıta dayalı çıkarımlar elde etmek mümkün değildir. Ancak, cerrahi tedavinin konservatif tedaviden üstün olduğu ve yaralanan bütün yapıların tamir/rekonstrükte edilmesinin şart olduğu konusunda bir fikir birliği vardır. ${ }^{[54-56]}$

\section{Primer Onarım}

Akut çoklu bağ yaralanmalarında, ÖÇB ve AÇB'lerin primer onarımı ile ilgili deneyimler sınırıdır. AÇB'nin femoral yapışma yerinden periostal ayrılması yani "peel-off" yaralanmalarında primer tamir ile kabul edilebilir sonuçlar bildirilmiştir. Bu tamirlerin başarılı olabilmesi için bağın gövdesinin kollajen yapı ve diziliminin sağlam olması ön şartı vardır. Artroskopik olarak bağın gövdesinden geçirilen çoklu dikişler, anatomik yapışma yerine açılan tünellerden geçirilerek mediyal femoral korteks köprüsü üzerinde bağlanabileceği gibi, insersiyona yerleştirilen dikiş kancaları da kullanılabilir. Bonanzinga ve ark., çoklu bağ yaralanması olan 13 olguda AÇB "peel-off” yaralanmasının primer tamiri ile başarılı sonuçlar bildirmişlerdir. ${ }^{\left[{ }^{[7]}\right.}$ Bağın primer onarımı propriyoseptif özelliklerini korurken, aynı zamanda çoklu bağ cerrahisinde zaten kısıtlı olan greft kaynaklarının da ekonomik olarak kullanımına imkân sağlar. ÖÇB peel-off yaralanması kemik avulsiyonlara göre çok daha nadirdir. Bağın gövdesinin sağlam olduğu durumlarda trans-osseöz dikişlerle onarım ile iyi sonuçlar olgu sunumu şeklinde bildirilmiştir. ${ }^{[58]}$

\section{Çapraz Bağların Kemik Avulsiyonlarında Artroskopik Tespit}

Çoklu bağ yaralanmaları sırasında oluşan ÖÇB'nin tibial eminensiyadan avulsiyon kırıkları artroskopik olarak başarıyla tedavi edilebilir. Eminensiyanın tespiti için, parça büyükse kanüle vidalar, küçükse bağın gövdesinden geçirilen çoklu dikişlerin tibia metafizinde bağlanması teknikleri kullanılabilir. Son zamanlarda geliştirilen güçlendirilmiş dikiş materyallerinin en az kanüle vidalar kadar sağlam tespit sağladığı ve çıkartılmaları gerekmediği için avantajlı oldukları gösterilmiştir. ${ }^{[59]}$

AÇB'nin tibial yapışma yerinden kemik avulsiyonlarında tercih edilen teknik, küçük bir postero-mediyal kesi ve parçanın arkadan öne kanüle vida ile tespitidir 
(Şekil 5). Yakın zamanda artroskopik olarak önden arkaya yapılan tespitler ile başarılı sonuçlar bildirilmiştir. Huang ve ark., postero-mediyal portalden görüntüleme sağlanırken; önden arkaya yerleştirilen kanüle vidalar ile tespit sağladıkları 18 hastada başarılı stabilite sonuçları rapor etmişlerdir. ${ }^{[60]} \mathrm{Bu}$ olgularda çoklu sütür tespiti de tek veya çift tibial tünel kullanılarak yapılabilir. ${ }^{[61,62]}$ Posterior portallerden görüntüleme yapılırken tibia anterior metafizinden açılan tünel veya tünellerle kırık yatağına ulaşıı, kırık redüksiyonu sonrası dikişler tibia anterior korteksi üzerinde veya tek tünel kullanılacaksa bir düğme implantı üzerinde bağlanabilir. ${ }^{[62]}$ Sabat ve ark., AÇB tibial avulsiyon kırığı olan 47 hastada açık ve artroskopik sütür tespitinin sonuçlarını karşılaştırmışlardır. ${ }^{[63]}$ IKDC skorları \%90 olguda normal ve normale yakın bulunurken stabilite ölçümlerinde artroskopik grup biraz daha üstün bulunmuş, bütün olgularda kırık kaynaması sağlanmıştır.

\section{ÇAPRAZ BAĞLARIN REKONSTRÜKSIYONU}

Diz çıkı̆̆ı sonrası gelişen çoklu bağ yaralanmalarında artroskopinin en önemli rolü çapraz bağların rekonstrüksiyonundadır. Rekonstrüksiyon için otogreft veya allogreftlerin kullanımı ile başarılı sonuçlar bildirilmiştir (Şekil 6). Boyut ve sayı kısıtlamasının olmaması; zaten ciddi bir travma geçirmiş dizde greft alımı ile ilave morbidite yaratmaması ve ek kesilerden kaçınarak cilt dolaşımının korunması allogreftlerin avantajlarıdır. ${ }^{64,65]}$ Buna karşılık, düşük de olsa hastalık taşınması riski, pahalı olmaları, mekanik güçlerinin otogreftlere göre daha zayıf olması ve biyolojik inkorporasyondaki sorunlar allogreftlerin olumsuz yönleridir. Allogreftlere ulaşım imkânı olmayan durumlarda karşı dizden otogreft alımı gündeme gelebilir.

Periferik yapıların onarımından önce çapraz bağların tünelleri açılmış, greftler yerleştirilmiş ve tespiti sağlanmış olmalıdır. Öncelikle AÇB rekonstrüksiyonu yapılarak diz redükte pozisyona getirilmeli, periferik yapılar bunun üzerine inşa edilmelidir. Hem ÖÇB hem de AÇB'nin yaralandığı durumlarda dizin anatomik pozisyonuna karar vermek zor olabilir, bu durumda normal tibial "step-off" oluşturulması ve artroskopide tibio-femoral ilişkinin gözlenmesi yararlıdır. ÖÇB ve $A C ̧ B$ beraber yaralandığı durumlarda hangi greftin önce gerilmesi gerektiği konusu tartışmalıdır. Klasik görüş AÇB greftine öncelik verirken; Kim ve ark., greftleri aynı anda gerdirip önce ÖÇB tespiti yapılması ile daha iyi stabilite sonuçları elde ettiklerini bildirmişlerdir. ${ }^{[6]}$ Her iki çapraz bağın rekonstrüksiyonu gerekli ise, daha kalın ve sağlam olan greft AÇB için kullanılmalıdır. Çapraz bağların rekonstrüksiyonunda, morbiditeyi azaltmak, kısıtlı greft kaynaklarını ve turnike süresini verimli kullanmak amacıyla; çapraz bağların tek demet rekonstrüksiyonları tercih edilir. ${ }^{[67]} \mathrm{Bu}$ işlemler sırasında tibial tarafta ÖÇB ve AÇB tünellerinin çakışmaması için aralarında yeterli mesafe olmasına dikkat edilmelidir. Turnike süresinin ekonomik kullanımı ve alışkın olunmayan pozisyonlarda çalışmaktan kaçınmak için, akut $\mathrm{AÇB}$ rekonstrüksiyonlarında inlay yerine transtibial teknikler tercih edilmelidir. Kronik olgularda, cerrahın deneyimine göre, tibial inlay yöntemi tercih edilebilir.

\section{Artroskopik AÇB Rekonstrüksiyonu}

Yazarların tercihi kombine ÖÇB ve AÇB yaralanmalarında önce $A C ̧ B$ tibial tünelinin açılmasıdır. Daha sonra $A C ̧ B$ femoral tünel, ÖÇB femoral tünel ve en son ÖÇB tibial tüneller açılmalıdır. Sıvı kaybını önlemek için tibial taraftaki tünellerin içine bu iş için geliştirilmiş tıkaçlar veya steril vazelin gazlı bez yerleştirilebilir. AÇB'nin tibial tüneli açlırken, görüntüleme interkondiler çentikten yapılabilir. ÖÇB sağlamsa hem enstrüman hem de görüntülemenin çentikten yapılması zor olabilir. Bu durumda postero-mediyal portalden görüntüleme ve enstrümanlar değişimli olarak kullanılabilir. AÇB tibial ayak izi akut olguların çoğunda saptanabilir, shaver ve radyofrekans cihazları ile bölge temizlendikten sonra, kılavuz sistemleri ile tibia anterior metafizinden ayak izinin ortasına bir kılavuz gönderilir. Kılavuz telinin tibia antero-mediyal metafizindeki giriş noktası, eklem çıkışında ölüm virajı adı verilen akut açılanmayı azaltmak için mümkün olduğunca distalden olmalıdır. Tibial tünelin antero-mediyal veya antero-lateral tibia metafızinden açılmasının klinik bir önemi yoktur. ${ }^{[68]}$ Ek yaralanmalara ve eldeki kesilere göre istenen bölgeden açılabilir. Kronik olgularda ve bağın ayak izinin saptanamadığı durumlarda tibial tünelin ekleme çıkış noktası, mediyal ve lateral tibial platoların ortasında yer alan çukur bölgede, eklem seviyesinin $1,5-2 \mathrm{~cm}$ distalindedir. Kılavuzun çukurun orta noktasının biraz lateralinde kalması, greftin seyri sırasında mediyal femoral kondile sürtünmesini engelleyecektir. Şüphede kalınan durumlarda skopi kontrolü yararlıdır (Şekil 7). Kılavuz çıkış noktasının doğruluğundan emin olunduktan sonra, greft çapında kanüle matkap ucu ile tibial tünel açılır. Bu sırada bir eğri küret ile kılavuz telinin posteriora ilerleyip nörovasküler yapılara zarar vermesi önlenmelidir. Femoral tünel dıştan içe veya içten dışa açılabilir (Şekil 8). Bazı yazarlar, içten dışa açılan tünellerde ikinci bir ölüm virajı ortaya çıktığını savunarak, dıştan içe açılmasını savunurlar. ${ }^{[69]}$ Ayrıca, içten dışa açılan tünellerde mediyal femoral kondile zarar verme ve interferans vidası yerleştirilmesi sırasında grefte zarar verme riskleri daha yüksektir. Hangi yöntem tercih edilirse edilsin, biyomekanik gücü ve işlevi daha yüksek olan antero-lateral demet rekonstrükte edilmelidir. ${ }^{[70]}$ Femoral tünel, saat 10 hizasında, eklem kıkırdağının 

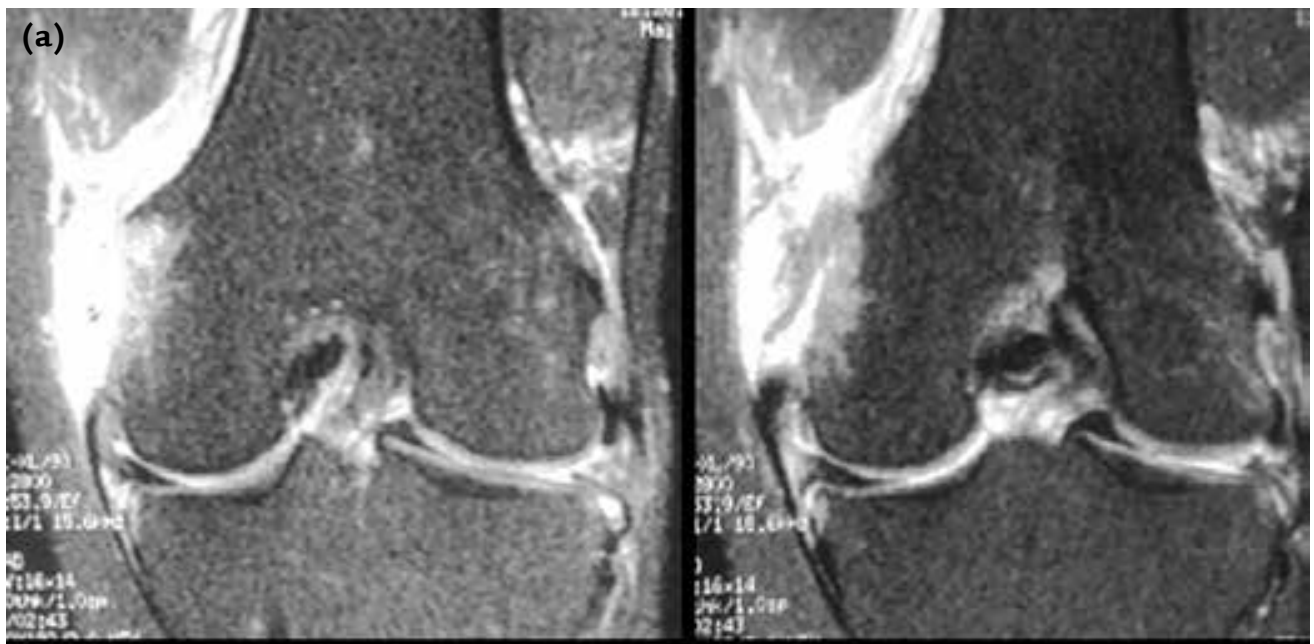

Şekil 5. a, b. AÇB'nin tibiadan ve IYB'nin femurdan kemik avulsiyonunda MR görüntüleri (a). Kırıkların vida tespiti sonrası grafiler

(b).
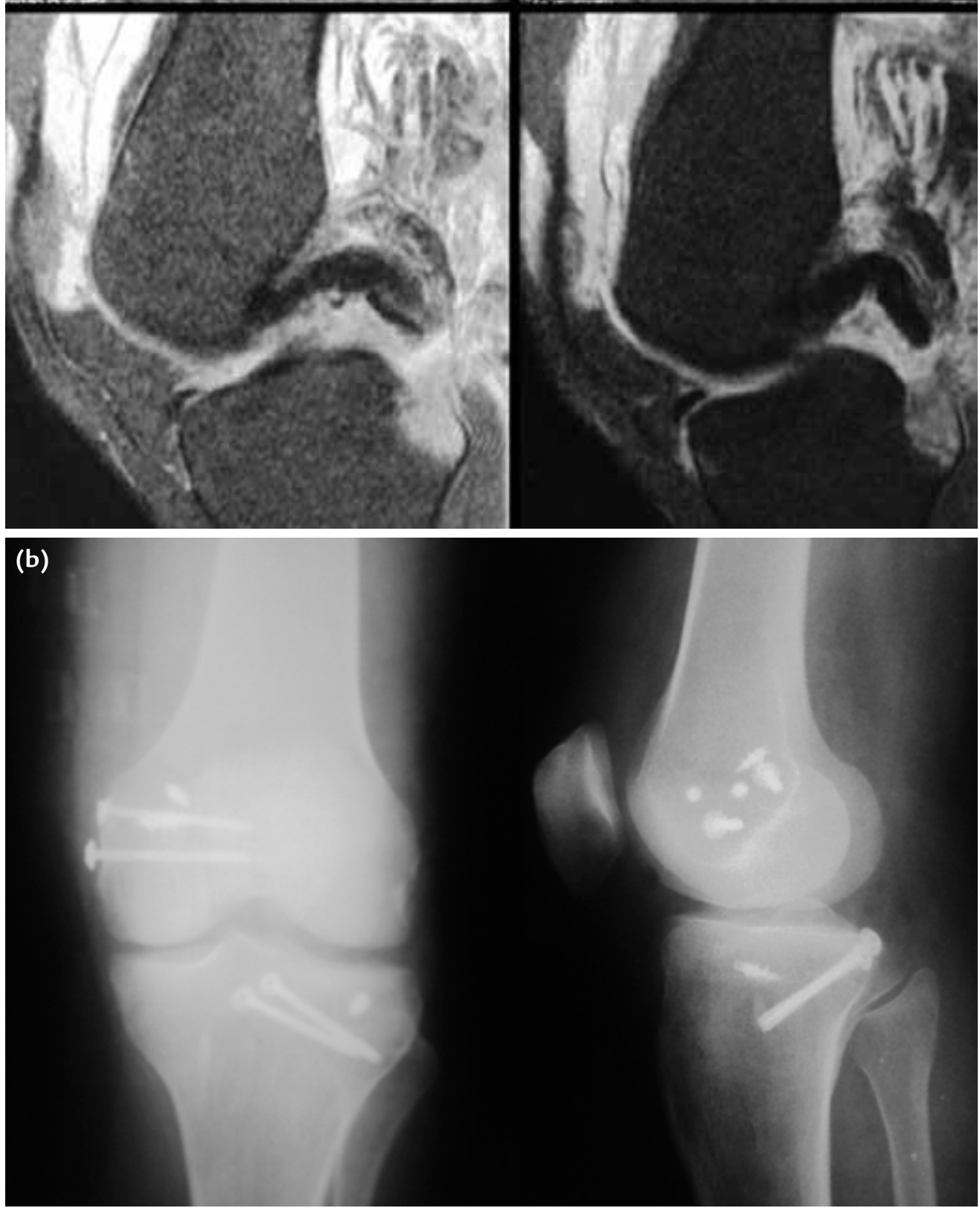


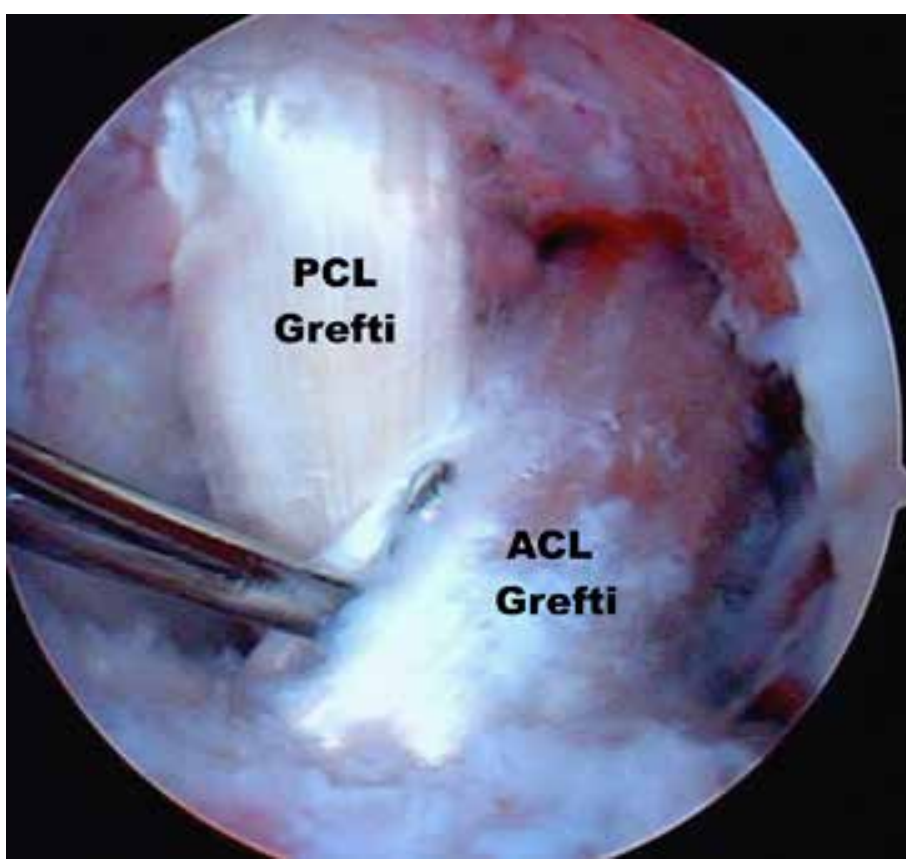

Şekil 6. ÖÇB ve AÇB'nin birlikte yaralandığı bir olguda, allogreft peroneal tendonlar ile her iki bağ rekonstrükte edilmiş.

Şekil 8. a, b. Femoral tünel açılması: içten dışa (a) ve dıştan içe (b) tünel hazırlanması.

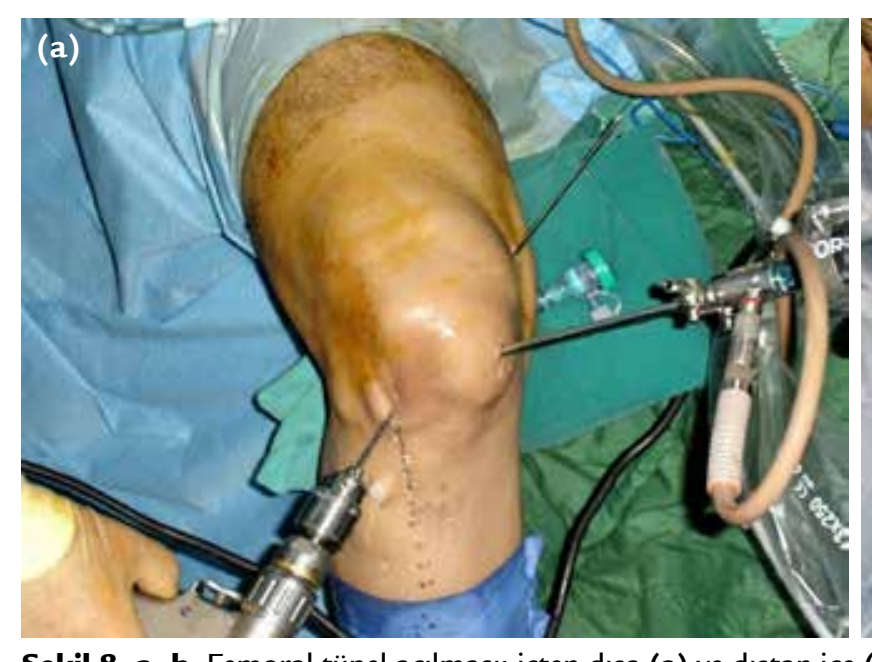

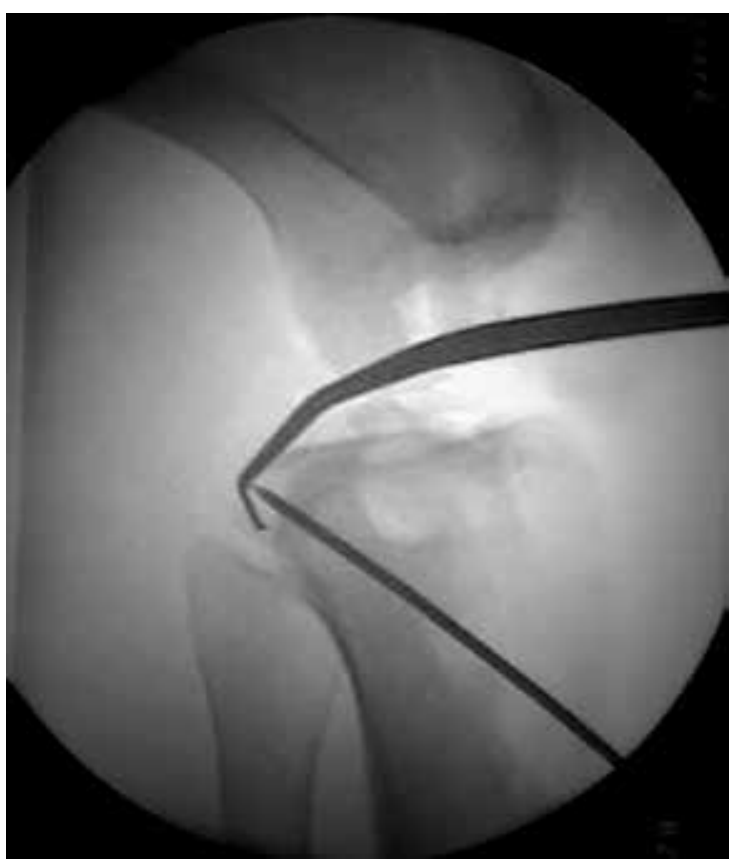

Şekil 7. AÇB tibial tünelinin skopi kontrolünde açılması.

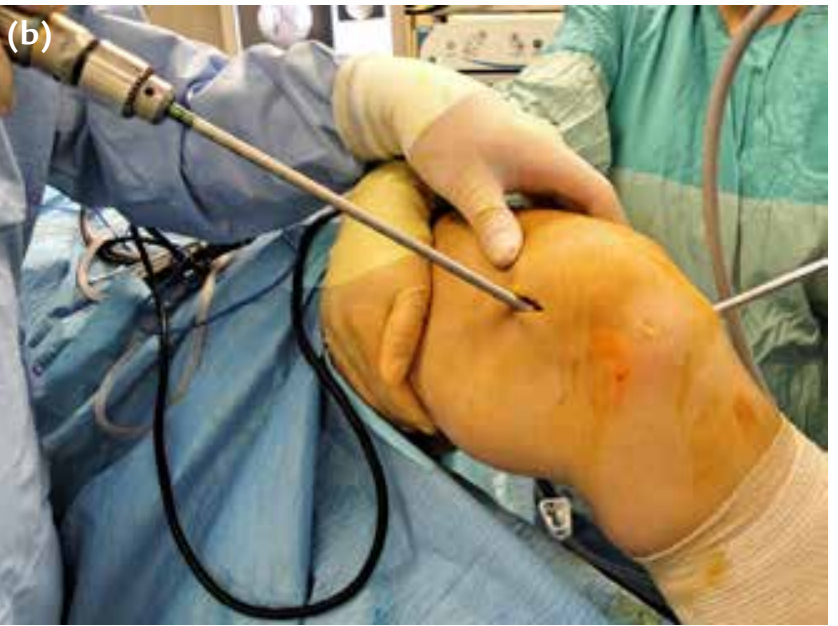

$2 \mathrm{~mm}$ arkasında ve AÇB ayak izi içinde kalacak şekilde açılmalıdır (Şekil 9).

Tüneller açıldıktan sonra sıra greftin yerleştirilmesine gelir. Greft tibial tünelden eklem içine alınıp, femoral tünel içine yönlendirilmelidir (Şekil 10). Kemik patellar tendon-kemik grefti kullanılıyor ise, femoral taraf kemik bloğu 20 mm'den büyük olmamalıdır, aksi halde tibial tünelin eklem içi çıkışında geçiş sorunları yaşanabilir. Kemik bloklu Aşil grefti tercih edildiyse, kemik blok tibial tünelde kalmalıdır. Greft femoral tünele yerleştirilip tespit edildikten sonra diz $25-30^{\circ}$ tam diz hareket siklusundan geçirilirken greft gerdirilir. Normal tibial "step-off" oluşturulup diz anatomik olarak redükte edildikten sonra tibial tespit yapilır. Greftin tespiti diz $70^{\circ}$ fleksiyonda ve öne çekmece uygulanırken yapılmalıdır. Tespit için femurda interferans vidaları veya askı sistemli düğme implantları kullanılabilir. Tibial tarafta interferans vidası tespiti, tibial tünelin eklem çıkısına mümkün olduğunca yakın yapılmalıdır. Yumuşak doku greftleri için kullanılacak interferans vidası çapı tünelden $1 \mathrm{~mm}$ daha büyük olmalıdır. Kemik bloklu greftlerde kemik kalitesine göre aynı çaplı vidalar 

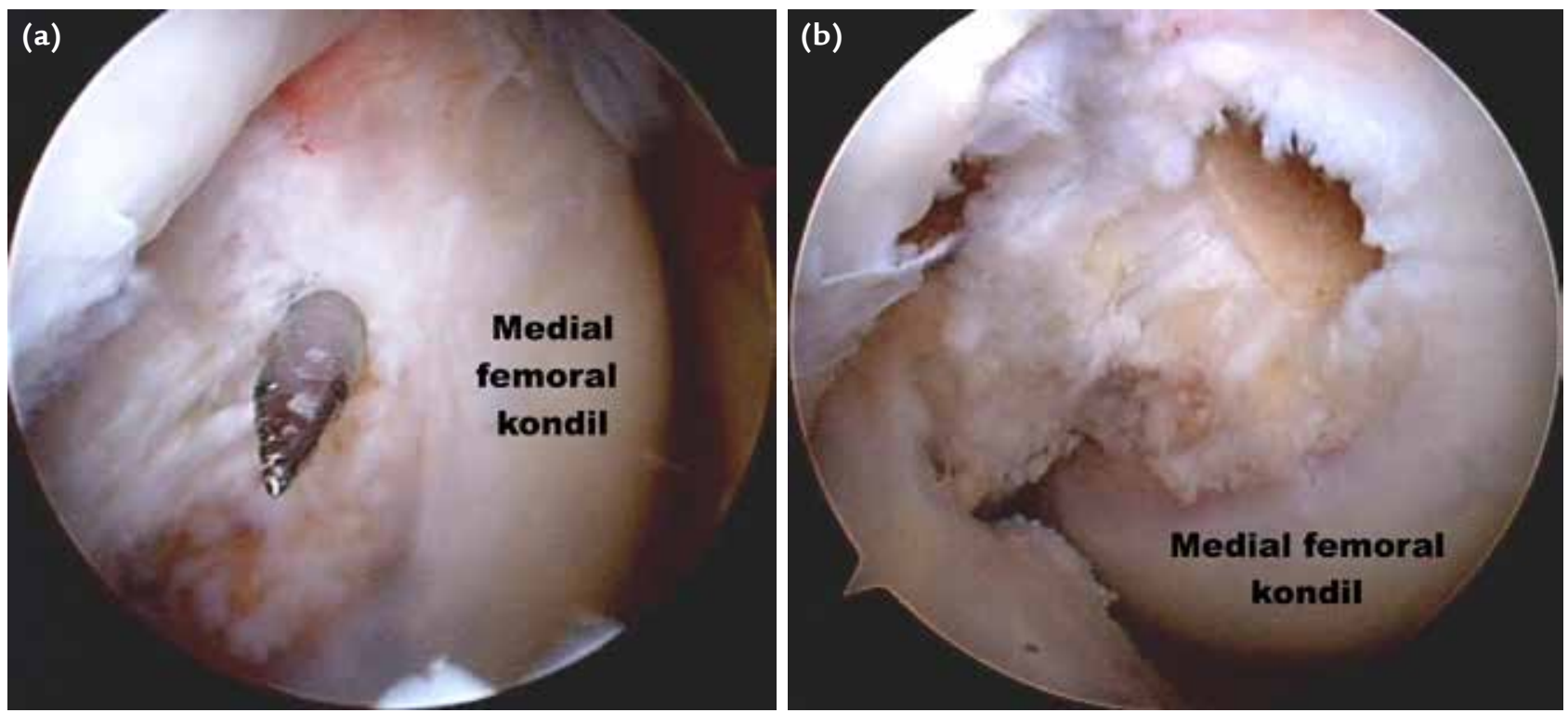

Şekil 9. a, b. Antero-lateral portalden bakışla AÇB femoral tünel hazırlanması: kılavuz teli yerleştirilmesi (a) ve tünel açıldıktan sonraki görüntü (b).

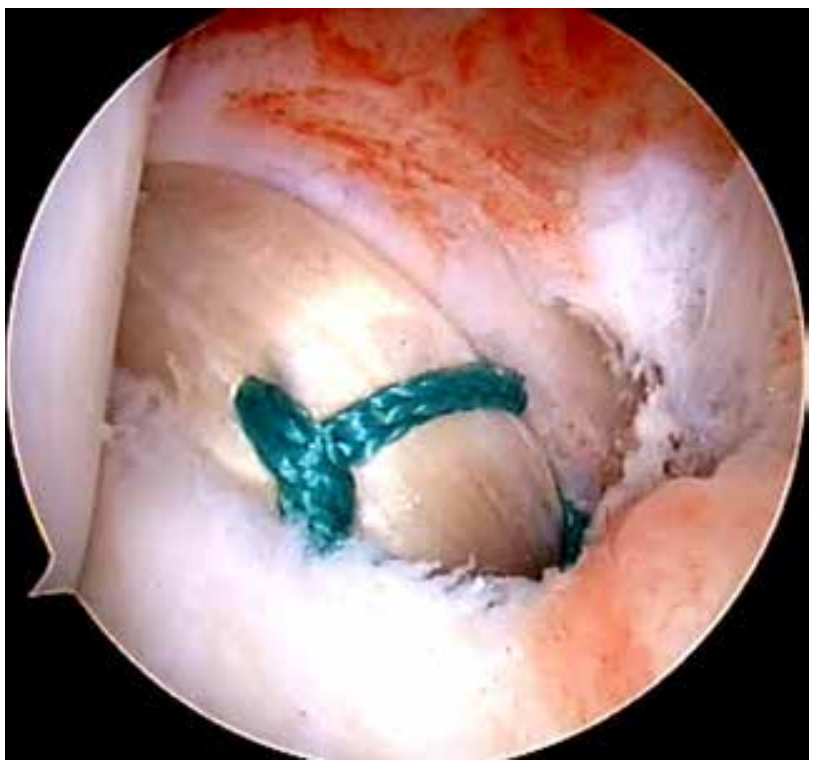

Şekil 10. Postero-mediyal portalden bakışla AÇB greftinin yerleştirilmiş görünümü.

tercih edilebilir. Tibial vida mümkün olduğunca uzun olmalıdır (30-35 mm), kemik kalitesinin zayıf olması nedeniyle, tibial tarafta ilave U-çivisi (staple) tespiti gerekli olabilir.

\section{Artroskopik ÖÇB Rekonstrüksiyonu}

Çoklu bağ yaralanmalarında ÖÇB rekonstrüksiyonu varsa, $\mathrm{AÇB}$ onarımından sonra ancak periferik yapıların tamirinden önce yapılmalıdır. Stannard ve ark., çoklu bağ yaralanmalarında artrofibrozis riskini azaltmak ve cerrahi süreyi kısaltmak açısından iki aşamalı bir cerrahi önerirler. ${ }^{[71]}$ ilk aşamada $A C ̧ B$ rekonstrüksiyonu ve periferik yapıların onarımı yapılır; 6-8 hafta sonra artroskopik ÖÇB rekonstrüksiyonu eklenir. Bu süre sonunda eğer gerekli ise artroskopik artroliz yapılarak diz hareket açıklığı da kazanılmış olur. Ancak dikkat edilmesi gereken nokta, ÖÇB rekonstrükte edilene kadar hastanın ilgili ekstremiteye yük vermeden mobilize olmasıdır. İki aşamalı cerrahinin en önemli sorunu; dizin normal kinematiği sağlanmadığı için, rekonstrükte edilen bağlarda anormal yüklenmelerin olması ve iki cerrahi sonrasında iki rehabilitasyon sürecinin morbiditesinin yüksek olmasıdır. Bu nedenlerden dolayı, günümüzde pek çok cerrahın tercihi bütün yaralanmış yapıların aynı anda rekonstrükte edilmesi ve mümkünse 3. haftada diz hareketlerine başlanmasıdır.

Çoklu bağ yaralanmalarında artroskopik ÖÇB rekonstrüksiyonu, primer cerrahiden bazı farklılıklar gösterir. Greft tercihi sıklıkla allogrefttir. Tünel yerleşimleri, eşlik edebilecek AÇB ve PLK yaralanmalarına yapılacak girişimleri engellemeyecek şekilde planlanmalıdır. Yazarların tercihi; tek demet, anatomik, aksesuvar antero-mediyal portalden femoral tünelin açıldığı rekonstrüksiyonlardır. Tünel yerleri bağın anatomik ayak izi içinde kalmalı ve mümkünse antero-mediyal demetin femoral ve tibial insersiyonları hedeflenmelidir. Femoral tünel, antero-mediyal portalden görüntüleme 


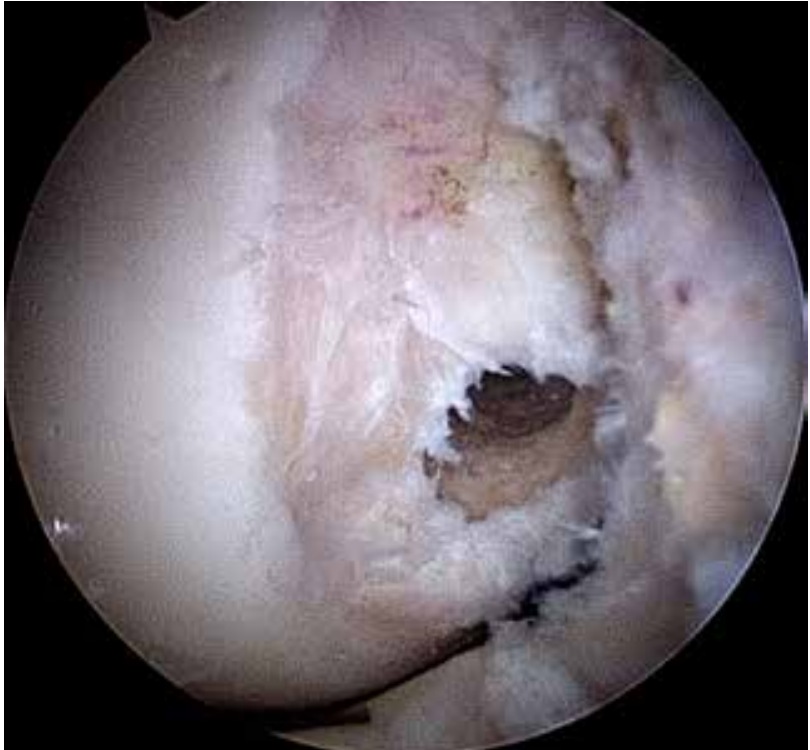

Şekil 11. Antero-mediyal portalden bakışla ÖÇB'nin femoral tünel yerleşiminin görünümü.

yapılırken aksesuvar alçak antero-mediyal portalden kılavuz telinin yerleştirilmesi ile açılır. Tünel yeri belirlendikten sonra, diz $130^{\circ}$ fleksiyona getirilerek kılavuz gönderilir. Kılavuz üzerinden matkap ucu yerleştirilirken mediyal femoral kondil kıkırdağına hasar vermemeye özen gösterilmelidir. İstenilen derinliğe kadar femoral tünel açılır (Şekil 11).

Tibial kılavuz $50^{\circ}$ açıya getirildikten sonra, tibia metafizinde $A C ̧ B$ tüneli veya iç yan onarım bölgesinden uzakta olacak şekilde tibial kılavuz teli yerleştirilir. Kılavuzun eklem içindeki çıkış noktası ÖÇB tibial ayak izinin anterior yarısında kalacak şekilde lateral menisküs ön boynuzu hizasında olmalıdır. Diz ekstansiyona getirildiğinde interkondiler çentik tavanında sıkışmanın olmadığı saptandıktan sonra greft çapı ile aynı kalınlıkta matkap ucu ile tünel açılır (Şekil 12).

Femoral tespit için askı sistemli düğme implantları tercih edilir. Tibial tespit yumuşak doku greftleri için tünel çapından $1 \mathrm{~mm}$ büyük biyoemilir interferans vidalarıyla, kemik bloklu greftler için tünel çapından 1 $\mathrm{mm}$ küçük metal interferans vidalarıyla yapılır. ÖÇB ve $A C ̧ B$ greftleri için tek bir geniş staple ile destek tespiti yapılabilir. $\mathrm{Diz} 15-20^{\circ}$ hareket siklusundan geçirildikten sonra greft tespiti yapılır (Şekil 13). Greft tespit açısı $20^{\circ}$ fleksiyonda olmalıdır. Kalın allogreftler kullanıldığında, interkondiler çentik içinde ÖÇB ve $A C ̧ B$ greftlerinin sürtünmesinden kaçınılmalıdır.

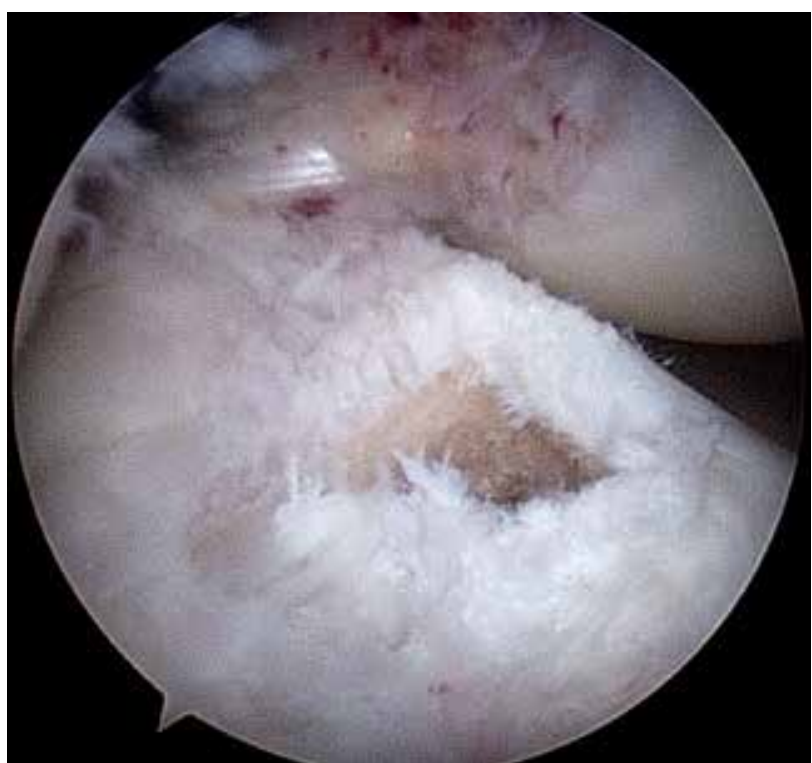

Şekil 12. Antero-lateral portalden bakışla ÖÇB tibial tünelinin yerleşimi.

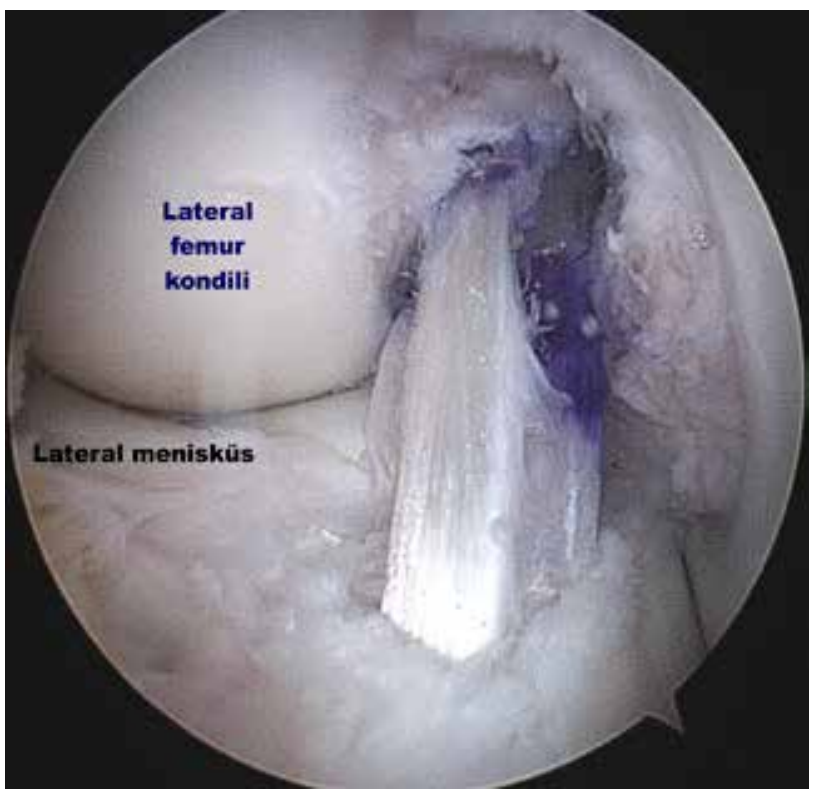

Şekil 13. Antero-mediyal portalden bakışla ÖÇB greftinin seyri.

\section{PERIFERIK YAPILARIN ONARIMI}

Çapraz bağların artroskopik rekonstrüksiyonu sonrasında, periferik yapıların onarımı açık cerrahi ile yapılır. Yaralanan yapıların çeşitliliği nedeniyle tek bir teknikten bahsetmek mümkün değildir, ancak belirli prensipler söz konusudur. Kollateral bağlar ve kapsüler yapıların doku kalitesi iyi ise primer tamir tercih edilir. Dokular primer tamir sonrası işlev görmeyecek kadar 
hasarlı ise akut dönemde primer rekonstrüksiyon yapılmalıdır. Mediyal tarafta primer tamir uygulamasının sonuçları başarılıdır ${ }^{72]}$ (Şekil 14), buna karşın PLK'nin primer tamiri ile yüksek başarısızlık oranları bildirilmiştir ve bazı yazarlar PLK yaralanmalarında primer rekonstrüksiyonu önerirler. ${ }^{[73-75]}$

Kapsüler yapılar ve menisküslere primer tamir yapılmalıdır. Bu işlem için küçük gövdeli dikiş çapaları kullanılmalı, büyük pul-vida implantlarından kaçınılmalıdır (Şekil 15). Onarımlar emilmeyen iplikler ile yapılmalıdır. Özellikle PLK yaralanmalarına eşlik eden antero-mediyal tibial rim kırıklarının internal tespiti çok önemlidir. Bu küçük kırıkların tespiti dizin stabilitesini önemli ölçüde arttırır. Bütün onarımlar tamamlandıktan sonra diz tam hareket açıklığı boyunca hareket ettirilmeli ve tamir sağlamlığı kontrol edilmelidir. Kural olarak; cerrahi sonunda stabil olmayan bir dizin daha sonra stabil olma şansı yoktur. Bütün onarımlar, dize en geç üç hafta içinde harekete başlayacak sağlamlıkta olmalıdır.

\section{SONUÇLAR}

Travmatik diz çıkıklarına bağlı çoklu bağ yaralanmalarının tedavi sonuçları, izole çapraz bağ yaralanmalarından çok farklıdır. Travmanın şiddeti, yaralanan yapıların fazlalığı, yüksek artrofibrozis ve kas atrofisi oranları nedeniyle amaç, hastayı günlük yaşam aktivitelerini ve hafif sporları yapabileceği stabil bir dize kavuşturmak olmalıdır. ÖÇB veya AÇB ile birlikte PLK yaralanması olan 13 serinin gözden geçirildiği Fransız Artroskopi Derneği'nin çalışmasında, olguların yaklaşık \%80'inde IKDC skorları A veya B olarak saptanmış, ortalama Lysholm skorları 90 civarında rapor edilmiştir. Bütün yaralanmış olan yapıların rekonstrüksiyonu ile en iyi sonuçlar elde edilmiştir. ${ }^{[76]}$ Yine Fransız Artroskopi Derneği'nin ÖÇB ve AÇB'nin birlikte rekonstrükte edildiği 53 olguluk çok merkezli çalışmasında, 49 aylık izlemde olguların 39'unda normal veya normale yakın IKDC skorları elde edilmiştir. ${ }^{[77]}$ Akut dönemde yapılan cerrahilerin sonuçları, kronik olgulara göre daha iyi bulunmuştur. Erken cerrahi tedavi ile stabil bir diz elde etmek ve hastaları günlük yaşam aktivitelerine döndürmek büyük oranda mümkün olsa bile, üst düzey spora dönüş her zaman mümkün değildir. Hirschmann ve ark., ilk altı hafta içinde cerrahi tedavi ettikleri kombine ÖÇB ve AÇB yaralanması olan 24 elit sporcuyu incelemişler, 19'unun spora dönebildiğini tespit etmişlerdir. ${ }^{[78]}$ Ancak, bu sporculardan sadece sekizi, yaralanma öncesi düzeyde spor yapabilme imkânı bulmuştur. Yaralanmanın şekli ve ciddiyeti nedeniyle, komplikasyonlar travmatik diz çıkıkları için önemini korumaya devam etmekte olup; başka hiçbir yaralanması olmayıp sadece diz çıkığı olan bir hasta
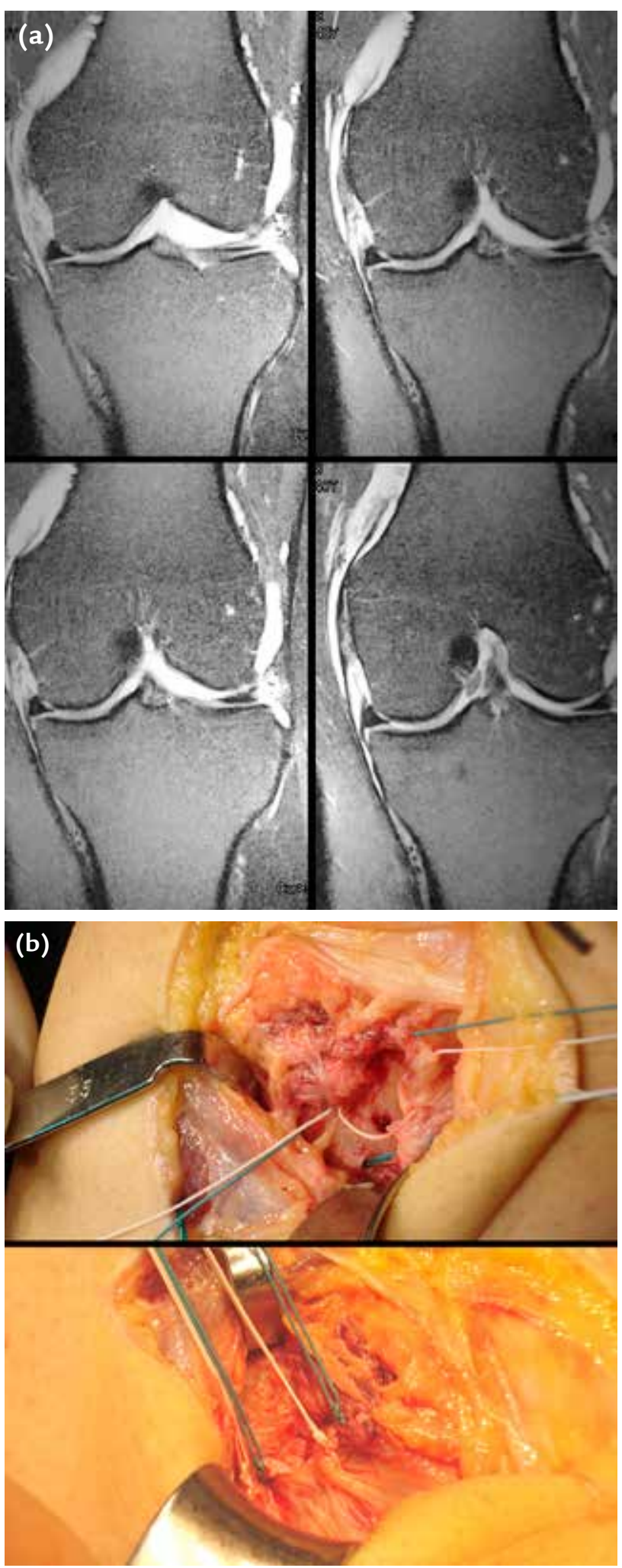

Şekil 14. a, b. IYB femoral yapışma yerinin ayrılmasında çoklu dikişler ile primer onarım: olgunun ameliyat öncesi MR görüntüleri (a) ve dikiş kancaları ile primer onarım uygulanması (b). 

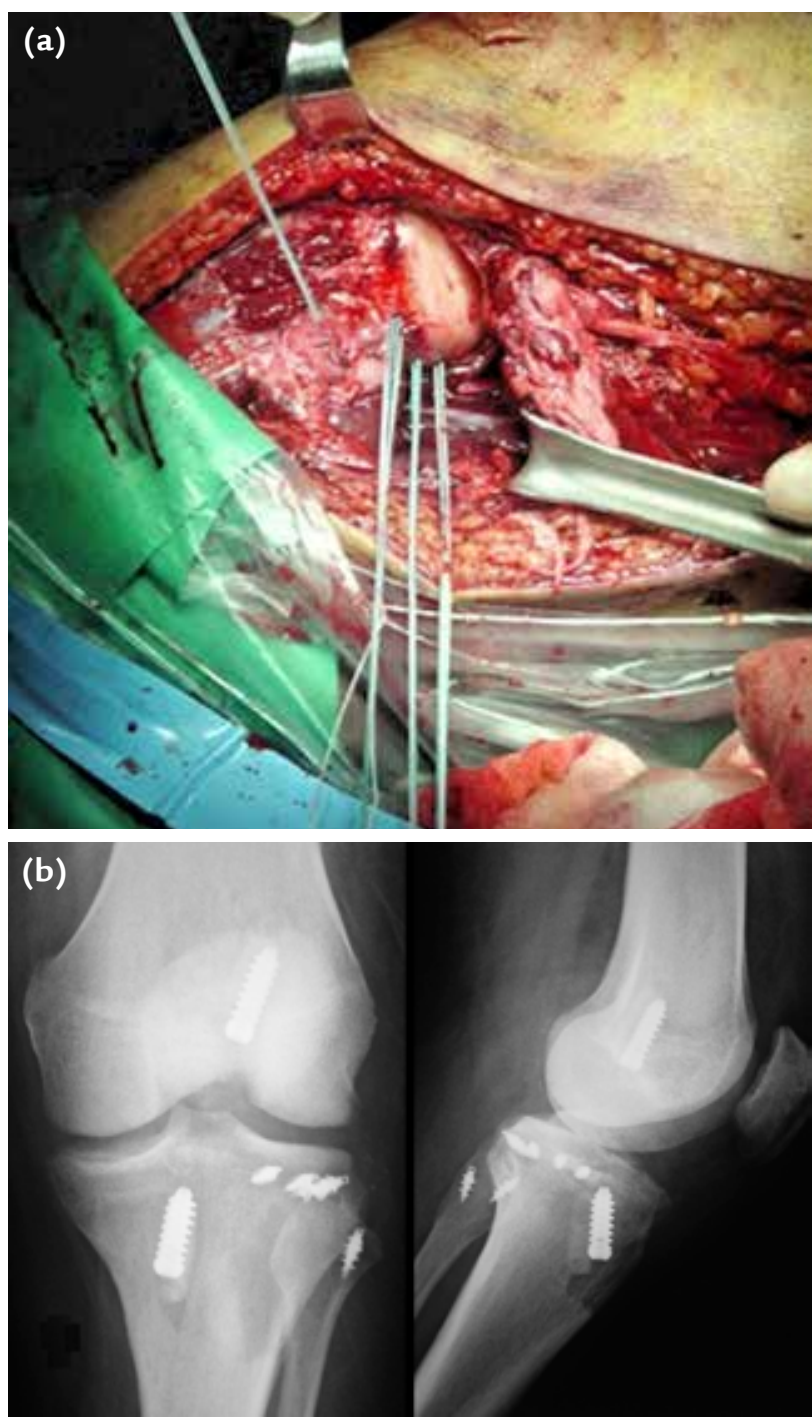

Şekil 15. a, b. Antero-lateral instabilitesi olan olguda lateral menisküsün periferik ayrılmasının dikiş kancaları ile onarımı: dikiş kancalarının yerleştirilmesi (a); ameliyat sonrası grafilerde dikiş kancaları ve ÖÇB rekonstrüksiyonuna ait görüntü (b).

gelişen komplikasyonlar nedeniyle kaybedilebilmektedir. Günümüzde ampütasyon ve ölüm gibi ciddi morbidite ve mortaliteye neden olan önemli komplikasyonlar oldukça nadirdir. Erken tanı ile ileride gelişebilecek olan bu komplikasyonların tedavisi, ekstremitenin fonksiyonel canlıığını ve devamlılığını sağlamada, hatta hayatın devamlılığını sürdürmede büyük önem taşımaktadır.

Diz çıkığı ve buna bağlı meydana gelen çoklu bağ yaralanmaları, dizde meydana gelebilecek en ciddi yaralanmalardan biridir. Çok sık görülmeyen ve bu nedenle yeterli deneyim oluşturulması zor olan bu kompleks yaralanmaların tedavisinde iyi sonuçta anahtarlar;
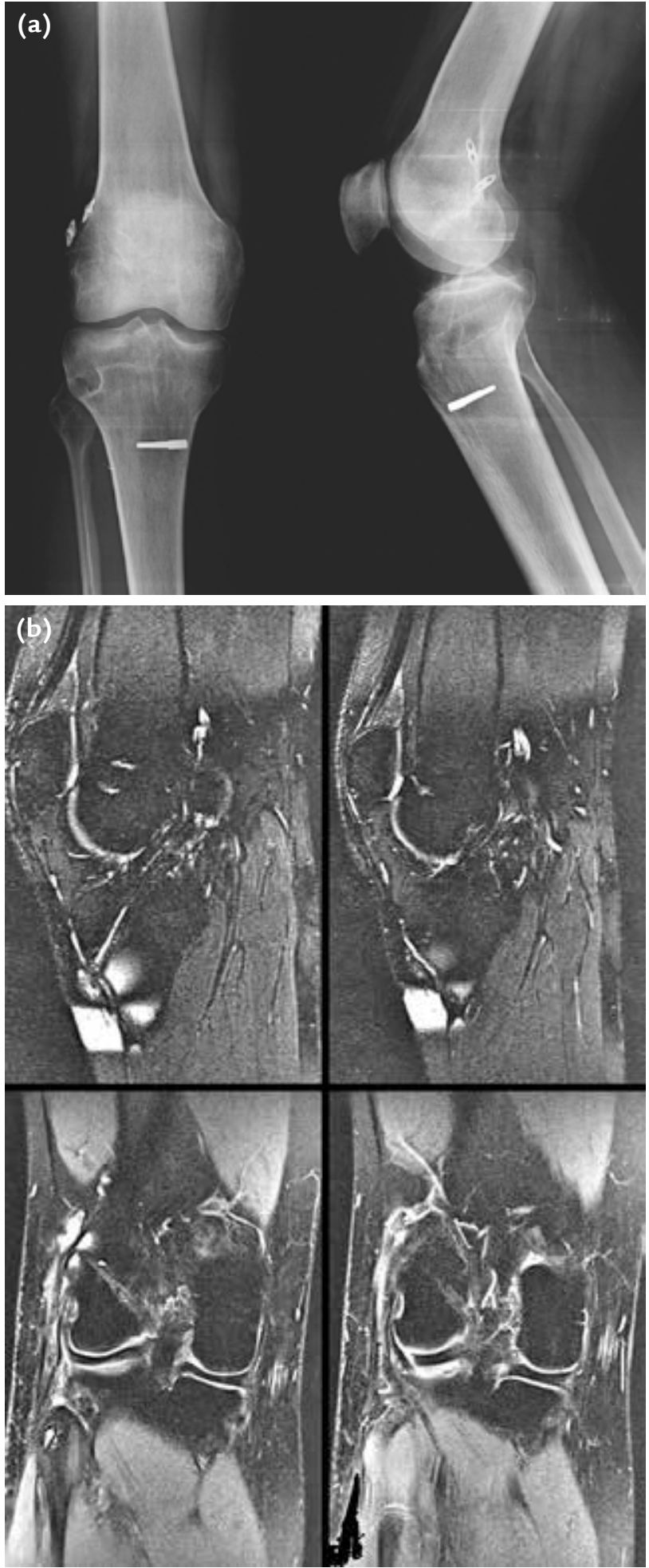

Şekil 16. a, b. ÖÇB ve PLK yaralanması nedeniyle tedavi edilen olgunun dört yıllık izlemdeki görüntüleri. ÖÇB için çift demet rekonstrüksiyon, PLK için LaPrade tipi rekonstrüksiyon uygulanmış: basarak grafilerde artroz bulgusu yok (a); kontrol MR görüntülerde greftlerin matürasyonu ve devamlılığı görülmekte (b); IKDC subjektif skoru A. ${ }^{[75]}$ 
- mükemmel anatomi bilgisi,

- yeterli greft ve implant materyali,

- ameliyatta birden fazla çözüm stratejisi uygulayabilecek deneyim ve hazırlık,

- mümkünse 3. haftada harekete başlayacak şekilde sağlam tespit ve

- fizyoterapi ile yakın koordinasyon olarak sıralanabilir ${ }^{[49,79]}$ (Şekil 16).

\section{KOMPLIKASYONLAR}

Diz çıkığı sonrası yapılan çoklu bağ cerrahisi sonrası komplikasyonlar nadir değildir. En sık görülen komplikasyonlar dizde hareket kısıtlılığı veya rezidüel instabilitedir. Cook ve ark., 133 çoklu bağ yaralanmasını içeren seride, yaralanmanın şiddeti ile komplikasyonlar arasında ilişki saptamışlardır. ${ }^{[65]}$ ikiden fazla bağ yaralandıysa ve akut cerrahide artrofibrozis riski daha yüksektir. Dört bağın yaralandığı durumlarda ise revizyon ihtiyacı daha yüksek bulunmuştur. Diğer komplikasyonlar şunlardır:

- Yara iyileşmesi sorunları ve enfeksiyon, zaten travmatize olmuş yumuşak dokular için önemli bir risktir. Mümkün ise cerrahi kesileri ekimotik cilt alanlarından uzaklaştırmalı ve greft alımı için ilave kesiler yerine allogreft kullanımı tercih edilmelidir.

- İyatrojenik damar/sinir yaralanması olabilir.

- Femoral kondilde osteonekroz, yaralanmaya bağlı olabileceği gibi AÇB tünelinin açılması sırasında mediyal kondile giden arterin zedelenmesi sonrası da olabilir. ${ }^{[80]}$

- Heterotopik ossifikasyon, diz çıkıkları sonrası \%34'e kadar yüksek oranlarda rapor edilmiştir. ${ }^{[81]}$

- Diz önü ağrısı, özellikle yeterli posterior stabilitenin sağlanamadığı durumlarda artmış patello-femoral yüklere bağlı ortaya çıkabilir.

\section{KAYNAKLAR}

1. Hegyes MS, Richardson MW, Miller MD. Knee dislocation. Complications of nonoperative and operative management. Clin Sports Med 2000;19(3):519-43. Crossref

2. Kayaalp A. Çoklu diz bağ yaralanmalarında ilk değerlendirme ve acil tedavi. Iç̧inde: Tandoğan NR, editör. Diz Bağ Yaralanmaları. Ankara: Tuna Matbaacılık; 2013. s 81-90.

3. Kennedy JC. Complete dislocation of the knee joint. J Bone Joint Surg Am 1963;45(5):889-904. Crossref

4. Schenck RC Jr. The dislocated knee. Instr Course Lect 1994:43:127-36.

5. Arom GA, Yeranosian MG, Petrigliano FA, Terrell RD, McAllister DR. The changing demographics of knee dislocation: a retrospective database review. Clin Orthop Relat Res 2014;472(9):2609-14. Crossref
6. Halvorson JJ, Anz A, Langfitt M, Deonanan JK, Scott A, Teasdall RD, Carroll EA. Vascular injury associated with extremity trauma: initial diagnosis and management. J Am Acad Orthop Surg 2011;19(8):495-504. Crossref

7. Werner BC, Gwathmey FW Jr, Higgins ST, Hart JM, Miller MD. Ultra-low velocity knee dislocations: patient characteristics, complications, and outcomes. Am J Sports Med 2014;42(2):358-63. Crossref

8. Georgiadis AG, Mohammad FH, Mizerik KT, Nypaver TJ, Shepard AD. Changing presentation of knee dislocation and vascular injury from high-energy trauma to low-energy falls in the morbidly obese. J Vasc Surg 2013;57(5):1196-203. Crossref

9. Ridley TJ, Cook S, Bollier M, McCarthy M, Gao Y, Wolf $B$, Amendola A. Effect of body mass index on patients with multiligamentous knee injuries. Arthroscopy 2014;30(11):1447-52. Crossref

10. Becker $\mathrm{EH}$, Watson JD, Dreese JC. Investigation of multiligamentous knee injury patterns with associated injuries presenting at a level I trauma center. J Orthop Trauma 2013;27(4):226-31. Crossref

11. Quinlan AG, Sharrard WJ. Posterolateral dislocation of the knee with capsular interposition. J Bone Joint Surg $\mathrm{Br}$ 1958;40-B(4):660-3. Crossref

12. Boisrenoult $P$, Lustig $S$, Bonneviale $P$, Leray $E$, Versier $G$, Neyret P, Rosset P, Saragaglia D. Vascular lesions associated with bicruciate and knee dislocation ligamentous injury. Orthop Traumatol Surg Res 2009;95(8):621-6. Crossref

13. Miranda FE, Dennis JW, Veldenz HC, Dovgan PS, Frykberg ER. Confirmation of the safety and accuracy of physical examination in the evaluation of knee dislocation for injury of the popliteal artery: a prospective study. J Trauma 2002;52(2):247-51. Crossref

14. Mills WJ, Barei DP, McNair P. The value of the ankle-brachial index for diagnosing arterial injury after knee dislocation: a prospective study. J Trauma 2004;56(6):1261-5. Crossref

15. Patterson BM, Agel J, Swiontkowski MF, Mackenzie EJ, Bosse MJ; LEAP Study Group. Knee dislocations with vascular injury: outcomes in the Lower Extremity Assessment Project (LEAP) Study. J Trauma 2007;63(4):855-8. Crossref

16. Stannard JP, Sheils TM, Lopez-Ben RR, McGwin G Jr, Robinson JT, Volgas DA. Vascular injuries in knee dislocations: the role of physical examination in determining the need for arteriography. J Bone Joint Surg Am 2004;86-A(5):910-5. Crossref

17. Wascher DC, Dvirnak PC, DeCoster TA. Knee dislocation: initial assessment and implications for treatment. J Orthop Trauma 1997;11(7):525-9. Crossref

18. Applebaum R, Yellin AE, Weaver FA, Oberg J, Pentecost $M$. Role of routine arteriography in blunt lower-extremity trauma. Am J Surg 1990;160(2):221-4. Crossref

19. Merritt AL, Wahl C. Initial assessment of the acute and chronic multiple-ligament injured (dislocated) knee. Sports Med Arthrosc 2011;19(2):93-103. Crossref

20. Redmond JM, Levy BA, Dajani KA, Cass JR, Cole PA. Detecting vascular injury in lower-extremity orthopedic trauma: the role of CT angiography. Orthopedics 2008;31(8):761-7. Crossref

21. Fanelli GC, Stannard JP, Stuart MJ, Macdonald PB, Marx RG, Whelan DB, Boyd JL, Levy BA.. Management of complex knee ligament injuries. Instr Course Lect 2011;60:523-35.

22. Nicandri GT, Chamberlain AM, Wahl CJ. Practical management of knee dislocations: a selective angiography protocol to detect limb threatening vascular injuries. Clin J Sport Med 2009;19(2):125-9. Crossref 
23. Bonnevialle P, Dubrana F, Galau B, Lustig S, Barbier O, Neyret P, Rosset P, Saragaglia D; la Société Française de Chirurgie Orthopédique et Traumatologique. Common peroneal nerve palsy complicating knee dislocation and bicruciate ligaments tears. Orthop Traumatol Surg Res 2010;96(1):64-9. Crossref

24. Peskun CJ, Chahal J, Steinfeld ZY, Whelan DB. Risk factors for peroneal nerve injury and recovery in knee dislocation. Clin Orthop Relat Res 2012;470(3):774-8. Crossref

25. Stewart JD. Foot drop: where, why and what to do? Pract Neurol 2008;8(3):158-69. Crossref

26. Irgit KS, Cush G. Tendon transfers for peroneal nerve injuries in the multiple ligament injured knee. J Knee Surg 2012;25(4):327-34. Crossref

27. Niall DM, Nutton RW, Keating JF. Palsy of the common peroneal nerve after traumatic dislocation of the knee. J Bone Joint Surg Br 2005;87-B(5):664-7. Crossref

28. Escobedo EM, Mills WJ, Hunter JC. The "reverse Segond" fracture: association with a tear of the posterior cruciate ligament and medial meniscus. AJR Am J Roentgenol 2002;178(4):979-83. Crossref

29. Twaddle BC, Bidwell TA, Chapman JR. Knee dislocations: where are the lesions? A prospective evaluation of surgical findings in 63 cases. J Orthop Trauma 2003;17(3):198-202. Crossref

30. Cohen AP, King D, Gibbon AJ. Impingement fracture of the anteromedial tibial margin: a radiographic sign of combined posterolateral complex and posterior cruciate ligament disruption. Skeletal Radiol 2001;30(2):114-6. Crossref

31. Stannard JP, Lopez R, Volgas D. Soft tissue injury of the knee after tibial plateau fractures. J Knee Surg 2010;23(4):187-92. Crossref

32. Krych AJ, Sousa PL, King AH, Engasser WM, Stuart MJ, Levy BA. Meniscal tears and articular cartilage damage in the dislocated knee. Knee Surg Sports Traumatol Arthrosc 2015;23(10):3019-25. Crossref

33. Lane CG, Warren R, Pearle AD. The pivot shift. J Am Acad Orthop Surg 2008;16(12):679-88. Crossref

34. Kim SJ, Kim HK. Reliability of the anterior drawer test, the pivot shift test, and the Lachman test. Clin Orthop Relat Res 1995;(317):237-42.

35. Clancy WG Jr, Shelbourne KD, Zoellner GB, Keene JS, Reider B, Rosenberg TD. Treatment of knee joint instability secondary to rupture of the posterior cruciate ligament. Report of a new procedure. J Bone Joint Surg Am 1983;65(3):310-22. Crossref

36. Patel DV, Allen AA, Warren RF, Wickiewicz TL, Simonian PT. The nonoperative treatment of acute, isolated (partial or complete) posterior cruciate ligament-deficient knees: an intermediate-term follow-up study. HSS J 2007;3(2):137-46. Crossref

37. Sekiya JK, Whiddon DR, Zehms CT, Miller MD. A clinically relevant assessment of posterior cruciate ligament and posterolateral corner injuries. Evaluation of isolated and combined deficiency. J Bone Joint Surg Am 2008;90(8):16217. Crossref

38. Gollehon DL, Torzilli PA, Warren RF. The role of the posterolateral and cruciate ligaments in the stability of the human knee. A biomechanical study. J Bone Joint Surg Am 1987;69(2):233-42. Crossref

39. Hughston JC, Andrews JR, Cross MJ, Moschi A. Classification of knee ligament instabilities: I. The medial compartment and cruciate ligaments. J Bone Joint Surg Am 1976;58(2):159-72. Crossref
40. Ranawat A, Baker CL 3rd, Henry S, Harner CD. Posterolateral corner injury of the knee: evaluation and management. J Am Acad Orthop Surg 2008;16(9):506-18. Crossref

41. Cooper DE. Tests for posterolateral instability of the knee in normal subjects: Results of examination under anesthesia. J Bone Joint Surg Am 1991;73(1):30-6. Crossref

42. Helgeson MD, Lehman RA Jr, Murphy KP. Initial evaluation of the acute and chronic multiple ligament injured knee. J Knee Surg 2005;18(3):213-9. Crossref

43. Levy BA, Fanelli GC, Whelan DB, Stannard JP, MacDonald PA, Boyd JL, Marx RG, Stuart MJ; Knee Dislocation Study Group. Controversies in the treatment of knee dislocations and multiligament reconstruction. J Am Acad Orthop Surg 2009;17(4):197-206. Crossref

44. Jung TM, Reinhardt C, Scheffler SU, Weiler A. Stress radiography to measure posterior cruciate ligament insufficiency: a comparison of five different techniques. Knee Surg Sports Traumatol Arthrosc 2006;14(11):1116-21. Crossref

45. Margheritini F, Mancini L, Mauro CS, Mariani PP. Stress radiography for quantifying posterior cruciate ligament deficiency. Arthroscopy 2003;19(7):706-11. Crossref

46. Puddu G, Giannì E, Chambat $P$, De Paulis $F$. The axial view in evaluating tibial translation in cases of insufficiency of the posterior cruciate ligament. Arthroscopy 2000;16(2):21720. Crossref

47. Dedmond BT, Almekinders LC. Operative versus nonoperative treatment of knee dislocations: a meta-analysis. Am J Knee Surg 2001;14(1):33-8.

48. Hollis JD, Daley BJ. 10-year review of knee dislocations: is arteriography always necessary? J Trauma 2005;59(3):672-5.

49. Howells NR, Brunton LR, Robinson J, Porteus AJ, Eldridge JD, Murray JR. Acute knee dislocation: an evidence based approach to the management of the multiligament injured knee. Injury 2011;42(11):1198-204. Crossref

50. Seroyer ST, Musahl V, Harner CD. Management of the acute knee dislocation: the Pittsburgh experience. Injury 2008;39(7):710-8. Crossref

51. Levy BA, Krych AJ, Shah JP, Morgan JA, Stuart MJ. Staged protocol for initial management of the dislocated knee. Knee Surg Sports Traumatol Arthrosc 2010;18(12):1630-7. Crossref

52. Levy BA, Dajani KA, Whelan DB, Stannard JP, Fanelli GC, Stuart MJ, Boyd JL, MacDonald PA, Marx RG. Decision making in the multiligament-injured knee: an evidence-based systematic review. Arthroscopy 2009;25(4):430-8. Crossref

53. Mook WR, Miller MD, Diduch DR, Hertel J, Boachie-Adjei Y, Hart JM. Multiple-ligament knee injuries: a systematic review of the timing of operative intervention and postoperative rehabilitation. J Bone Joint Surg Am 2009;91(12):2946-57. Crossref

54. Dwyer T, Marx RG, Whelan D. Outcomes of treatment of multiple ligament knee injuries. J Knee Surg 2012;25(4):31726. Crossref

55. Peskun CJ, Whelan DB. Outcomes of operative and nonoperative treatment of multiligament knee injuries: an evidence-based review. Sports Med Arthrosc 2011;19(2):16773. Crossref

56. Wong $\mathrm{CH}$, Tan JL, Chang HC, Khin LW, Low CO. Knee dislocations --a retrospective study comparing operative versus closed immobilization treatment outcomes. Knee Surg Sports Traumatol Arthrosc 2004;12(6):540-4. Crossref 
57. Bonanzinga $T$, Zhang $H$, Song GY, Zhang J, Signorelli C, Feng $\mathrm{H}$. Is PLC repair of a peel-off femoral lesion an effective option in a multiligament setting? Knee Surg Sports Traumatol Arthrosc 2015;23(10):2936-42. Crossref

58. Ahn JH, Han KY, Yu IS, Koh KH. Arthroscopic treatment for tibial "Peel off" tears in anterior cruciate ligament-case report. Eur J Orthop Surg Traumatol 2013;23 Suppl 2:S2515. Crossref

59. Bong MR, Romero A, Kubiak E, lesaka K, Heywood CS, Kummer F, Rosen J, Jazrawi L. Suture versus screw fixation of displaced tibial eminence fractures: a biomechanical comparison. Arthroscopy 2005;21(10):1172-6. Crossref

60. Huang W, Gong X, Rahul M, Priyanka S, Wang C, Liang X, Ding $G$, Hu N. Anterior arthroscopic-assisted fixation of posterior cruciate ligament avulsion fractures. Eur J Med Res 2015;20(1):88. Crossref

61. Gui J, Wang L, Jiang Y, Wang Q, Yu Z, Gu Q. Single-tunnel suture fixation of posterior cruciate ligament avulsion fracture. Arthroscopy 2009;25(1):78-85. Crossref

62. Chen SY, Cheng CY, Chang SS, Tsai MC, Chiu CH, Chen AC, Chan YS. Arthroscopic suture fixation for avulsion fractures in the tibial attachment of the posterior cruciate ligament. Arthroscopy 2012;28(10):1454-63. Crossref

63. Zhao J, He Y, Wang J. Arthroscopic treatment of acute tibial avulsion fracture of the posterior cruciate ligament with suture fixation technique through Y-shaped bone tunnels. Arthroscopy 2006;22(2):172-81. Crossref

64. Sabat D, Jain A, Kumar V. Displaced posterior cruciate ligament avulsion fractures: a retrospective comparative study between open posterior approach and arthroscopic single-tunnel suture fixation. Arthroscopy 2015;32(1):44-53. Crossref

65. CookS, RidleyTJ, McCarthy MA, GaoY, WolfBR, Amendola A, Bollier MJ. Surgical treatment of multiligament knee injuries. Knee Surg Sports Traumatol Arthrosc 2015;23(10):2983-91. Crossref

66. Kim SJ, Kim SH, Jung M, Kim JM, Lee SW. Does sequence of graft tensioning affect outcomes in combined anterior and posterior cruciate ligament reconstructions? Clin Orthop Relat Res 2015;473(1):235-43. Crossref

67. Fanelli GC, Edson CJ. Surgical treatment of combined PCL-ACL medial and lateral side injuries (global laxity): surgical technique and 2- to 18-year results. J Knee Surg 2012;25(4):307-16. Crossref

68. Wong T, Wang CJ, Weng LH, Hsu SL, Chou WY, Chen JM, Chan YS. Functional outcomes of arthroscopic posterior cruciate ligament reconstruction: comparison of anteromedial and anterolateral trans-tibia approach. Arch Orthop Trauma Surg 2009;129(3):315-21. Crossref

69. Schoderbek RJ Jr, Golish SR, Rubino LJ, Oliviero JA, Hart JM, Miller MD. The graft/femoral tunnel angles in posterior cruciate ligament reconstruction: a comparison of 3 techniques for femoral tunnel placement. J Knee Surg 2009;22(2):106-10. Crossref
70. Markolf KL, Feeley BT, Tejwani SG, Martin DE, McAllister DR. Changes in knee laxity and ligament force after sectioning the postero-medial bundle of the posterior cruciate ligament. Arthroscopy 2006;22(10):1100-6. Crossref

71. Stannard JP, Black BS, Azbell C, Volgas DA. Posteromedial corner injury in knee dislocations. J Knee Surg 2012;25(5):429-34. Crossref

72. Kovachevich R, Shah JP, Arens AM, Stuart MJ, Dahm DL, Levy BA. Operative management of the medial collateral ligament in the multi-ligament injured knee: an evidence-based systematic review. Knee Surg Sports Traumatol Arthrosc 2009;17(7):823-9. Crossref

73. Geeslin AG, Moulton SG, LaPrade RF. A systematic review of the outcomes of postero-lateral corner knee injuries, part 1: Surgical treatment of acute injuries. Am J Sports Med 2015;44(5):1336-42. Crossref

74. Black BS, Stannard JP. Repair versus reconstruction in acute postero-lateral instability of the knee. Sports Med Arthrosc 2015;23(1):22-6. Crossref

75. Bennett DL, George MJ, El-Khoury GY, Stanley MD, Sundaram M. Anterior rim tibial plateau fractures and posterolateral corner knee injury. Emerg Radiol 2003;10(2):76-83. Crossref

76. Rochecongar G, Plaweski S, Azar M, Demey G, Arndt J, Louis ML, Limozin R, Djian P, Sonnery-Cottet B, Bousquet V, Bajard X, Wajsfisz A, Boisrenoult P; French Society for Arthroscopy (Société Française d'Arthroscopie, SFA). Management of combined anterior or posterior cruciate ligament and postero-lateral corner injuries: a systematic review. Orthop Traumatol Surg Res 2014;100(8 Suppl):S371-8. Crossref

77. Wajsfisz A, Bajard X, Plaweski S, Djian P, Demey G, Limozin R, Bousquet V, Rocheconcar G, Louis ML, Arndt J, Azar M, Sonnery-Cottet B, Boisrenoult P; French Arthroscopy Society (SFA). Surgical management of combined anterior or posterior cruciate ligament and posterolateral corner tears: for what functional results? Orthop Traumatol Surg Res 2014;100(8 Suppl):S379-83. Crossref

78. Hirschmann MT, Iranpour F, MüllerW, Friederich NF. Surgical treatment of complex bicruciate knee ligament injuries in elite athletes: what long-term outcome can we expect? Am J Sports Med 2010;38(6):1103-9. Crossref

79. Gella S, Whelan DB, Stannard JP, MacDonald PB. Acute Management and Surgical Timing of the Multiligamentinjured Knee. Instr Course Lect 2015;64:521-30.

80. Hunter JC, Escobedo EM, Routt ML. Osteonecrosis of the femoral condyles following traumatic dislocation of the knee. Skeletal Radiol 1996;25(3):276-8. Crossref

81. Whelan DB, Dold AP, Trajkovski T, Chahal J. Risk factors for the development of heterotopic ossification after knee dislocation. Clin Orthop Relat Res 2014;472(9):2698-704. Crossref 